OPEN ACCESS

Edited by:

Karine Clément,

Sorbonne Universités, France

Reviewed by:

Jörn M. Schattenberg,

Johannes Gutenberg University Mainz,

Germany

Sean L. McGee,

Deakin University, Australia

${ }^{*}$ Correspondence:

Manu V. Chakravarthy

mchakravarthy@axcellahealth.com

Specialty section:

This article was submitted to

Obesity,

a section of the journal

Frontiers in Endocrinology

Received: 06 August 2020

Accepted: 16 November 2020

Published: 23 December 2020

Citation:

Chakravarthy MV, Siddiqui MS, Forsgren MF and Sanyal AJ (2020) Harnessing Muscle-Liver Crosstalk to

Treat Nonalcoholic Steatohepatitis.

Front. Endocrinol. 11:592373.

doi: 10.3389/fendo.2020.592373

\section{Harnessing Muscle-Liver Crosstalk to Treat Nonalcoholic Steatohepatitis}

\author{
Manu V. Chakravarthy ${ }^{1 *}$, Mohammad S. Siddiqui ${ }^{2}$, Mikael F. Forsgren ${ }^{3,4,5}$ \\ and Arun J. Sanyal ${ }^{2}$ \\ ${ }^{1}$ Axcella Health, Inc., Cambridge, MA, United States, ${ }^{2}$ Department of Internal Medicine and Division of Gastroenterology, \\ Hepatology and Nutrition, Virginia Commonwealth University, Richmond, VA, United States, ${ }^{3}$ Department of Health, \\ Medicine and Caring Sciences, Linköping University, Linköping, Sweden, ${ }^{4}$ Center for Medical Image Science and \\ Visualization, Linköping University, Linköping, Sweden, ${ }^{5}$ AMRA Medical AB, Linköping, Sweden
}

Non-alcoholic fatty liver disease (NAFLD) has reached epidemic proportions, affecting an estimated one-quarter of the world's adult population. Multiple organ systems have been implicated in the pathophysiology of NAFLD; however, the role of skeletal muscle has until recently been largely overlooked. A growing body of evidence places skeletal muscle-via its impact on insulin resistance and systemic inflammation-and the muscle-liver axis at the center of the NAFLD pathogenic cascade. Population-based studies suggest that sarcopenia is an effect-modifier across the NAFLD spectrum in that it is tightly linked to an increased risk of non-alcoholic fatty liver, non-alcoholic steatohepatitis (NASH), and advanced liver fibrosis, all independent of obesity and insulin resistance. Longitudinal studies suggest that increases in skeletal muscle mass over time may both reduce the incidence of NAFLD and improve preexisting NAFLD. Adverse muscle composition, comprising both low muscle volume and high muscle fat infiltration (myosteatosis), is highly prevalent in patients with NAFLD. The risk of functional disability conferred by low muscle volume in NAFLD is further exacerbated by the presence of myosteatosis, which is twice as common in NAFLD as in other chronic liver diseases. Crosstalk between muscle and liver is influenced by several factors, including obesity, physical inactivity, ectopic fat deposition, oxidative stress, and proinflammatory mediators. In this perspective review, we discuss key pathophysiological processes driving sarcopenia in NAFLD: anabolic resistance, insulin resistance, metabolic inflexibility and systemic inflammation. Interventions that modify muscle quantity (mass), muscle quality (fat), and physical function by simultaneously engaging multiple targets and pathways implicated in muscle-liver crosstalk may be required to address the multifactorial pathogenesis of NAFLD/NASH and provide effective and durable therapies.

Keywords: NASH, insulin resistance, lipotoxicity, myosteatosis, inflammation, skeletal muscle, adipose tissue, obesity 


\section{INTRODUCTION}

Tremendous progress has been made in our understanding of the mechanisms underlying non-alcoholic fatty liver disease (NAFLD) (1-3), including the identification of several molecular pathways impacting a number of cell types (hepatocytes, macrophages, stellate cells) and organ systems, ranging from the liver to adipose tissue, the gut, immune system, and kidney $(4,5)$. Yet, few if any of these pathways explicitly involve skeletal muscle, the principal organ responsible for glucose disposal (6) and energy homeostasis (7), key processes that can impact the core pathogenesis of a systemic metabolic disease such as NAFLD (8).

Over the past few decades, the epidemics of obesity and type 2 diabetes (T2D) have continued unabated (9). Given the known bidirectional nature of the metabolic impact of obesity/T2D and NAFLD (10), the trajectory of NAFLD has likewise increased significantly, reaching epidemic proportions, with nearly a quarter of the globe afflicted with the condition (11). Nonalcoholic steatohepatitis (NASH), the more severe form of NAFLD, with manifestations of fibroinflammatory change (12), has a global prevalence as high as $37.3 \%$ among individuals with T2D (13), contributes to increasing rates of cirrhosis $(14,15)$, and is rapidly emerging as the leading cause of liver transplantation $(16,17)$. Global prevalence rates of cirrhosis continue to increase (18) along with the proportion of cirrhotic subjects with obesity (19). Sarcopenia is common in subjects with cirrhosis, with an estimated prevalence of $40 \%-70 \%$, as well as in obese individuals $(20,21)$. In a Korean nationwide survey, more than $12 \%$ of all patients diagnosed with NAFLD had sarcopenia independent of obesity and insulin resistance (22), and up to $30 \%$ of sarcopenic subjects without metabolic syndrome and obesity had NAFLD (23). Thus, it appears that the bidirectional muscleliver axis could play a significant pathophysiological role across the full spectrum of chronic liver disease.

In this perspective review, we discuss three main topics: (i) current clinical evidence linking sarcopenia and NAFLD/NASH; (ii) the clinical relevance of muscle composition to physical function in NAFLD; and (iii) key pathophysiological processes and molecular mediators underpinning the muscle-liver axis in NAFLD/NASH. Among these latter processes, the review explores two key physiological concepts, anabolic resistance and metabolic inflexibility, as potential avenues for novel therapeutic strategies to address the complex and multifactorial pathogenesis of NAFLD/NASH.

\section{SARCOPENIA-DEFINITIONS AND MEASUREMENTS}

\section{Definitions}

The term "sarcopenia" was first introduced by Irwin Rosenberg in 1989 to describe the age-related decline in muscle mass among the elderly (24). Muscle mass accounts for $\sim 45 \%$ of body mass, and once people reach 50 years of age, they lose $\sim 1 \%-2 \%$ of their muscle mass per year (25). The European
Working Group on Sarcopenia in Older People (EWGSOP) defines sarcopenia as generalized and progressive loss of three parameters: (i) muscle strength, (ii) muscle quantity/quality, and (iii) physical performance (26). Loss of muscle quality, for example as a result of myosteatosis, has also been directly linked to low physical function, poor clinical outcomes, and mortality (27).

Sarcopenia is clinically meaningful as it results in functional impairment with loss of strength, disability, frailty, loss of autonomy, and increased risk of falls and mortality, and therefore fundamentally affects how an individual feels and functions (Figure 1) (28-30). Although sarcopenia was once regarded as part of normal aging (31), nowadays, it is increasingly recognized as a progressive disease that is associated with increased risk of several common chronic metabolic disorders, including obesity, type 2 diabetes, metabolic syndrome, osteoporosis, cardiovascular disease, and cancer (Figure 1) (32-37). Sarcopenia is also acknowledged as a common complication and mortality risk factor in patients with cirrhosis and end-stage liver disease (ESLD) $(38,39)$. However, there are limited data directly linking sarcopenia to outcomes in NASH.

\section{Measurements}

The Foundation for the National Institutes of Health Sarcopenia Project, comprising a pooled sample of 26,625 participants [ $57 \%$ women, mean age in men 75.2 ( \pm 6.1 standard deviation) and in women $78.6( \pm 5.9)$ years], recommended the following cutoff points for weakness and low lean mass: handgrip strength $<26 \mathrm{~kg}$ for men and $<16 \mathrm{~kg}$ for women, and appendicular lean body mass [measured by dual-energy X-ray absorptiometry (DXA) and adjusted for body mass index (BMI) $]<0.789$ for men and $<0.512$ for women (40). Recommendations from the EWGSOP (26) to assess for evidence of sarcopenia include strength assessments with the use of handgrip strength $(<27 \mathrm{~kg}$ for men, $<16 \mathrm{~kg}$ for women) and chair stand ( $>15 \mathrm{~s}$ for 5 rises); to confirm sarcopenia by detection of low muscle quantity and quality, DXA is advised in clinical practice, and DXA, bioelectrical impedance analysis, computerized tomography (CT), or magnetic resonance imaging (MRI) in research studies with appendicular skeletal muscle mass $<20 \mathrm{~kg}(<7.0$ $\left.\mathrm{kg} / \mathrm{m}^{2}\right)$ for men and $<15 \mathrm{~kg}\left(<5.5 \mathrm{~kg} / \mathrm{m}^{2}\right)$ for women. To determine severity of sarcopenia, recommendations include physical performance measures of gait speed $(\leq 0.8 \mathrm{~m} / \mathrm{s})$, short performance physical battery ( $\leq 8$ point score), timed-up-and-go test $(\geq 20 \mathrm{~s})$, and $400-\mathrm{m}$ walk test (non-completion or $\geq 6$ min for completion). While these are the current EWGSOP recommendations, it is important to acknowledge that some of these assessments (e.g., gait speed, 400-m walk) may also depend on cardiopulmonary fitness. In addition, assessment of strength by hand grip and chair stand as proposed addresses two distinct muscle groups, and consequently, could impact prognosis differently. Thus, additional studies are likely needed to further delineate the contribution of cardiopulmonary fitness to these tests designed to measure sarcopenia per se, as well as when to use one strength test or the other. 


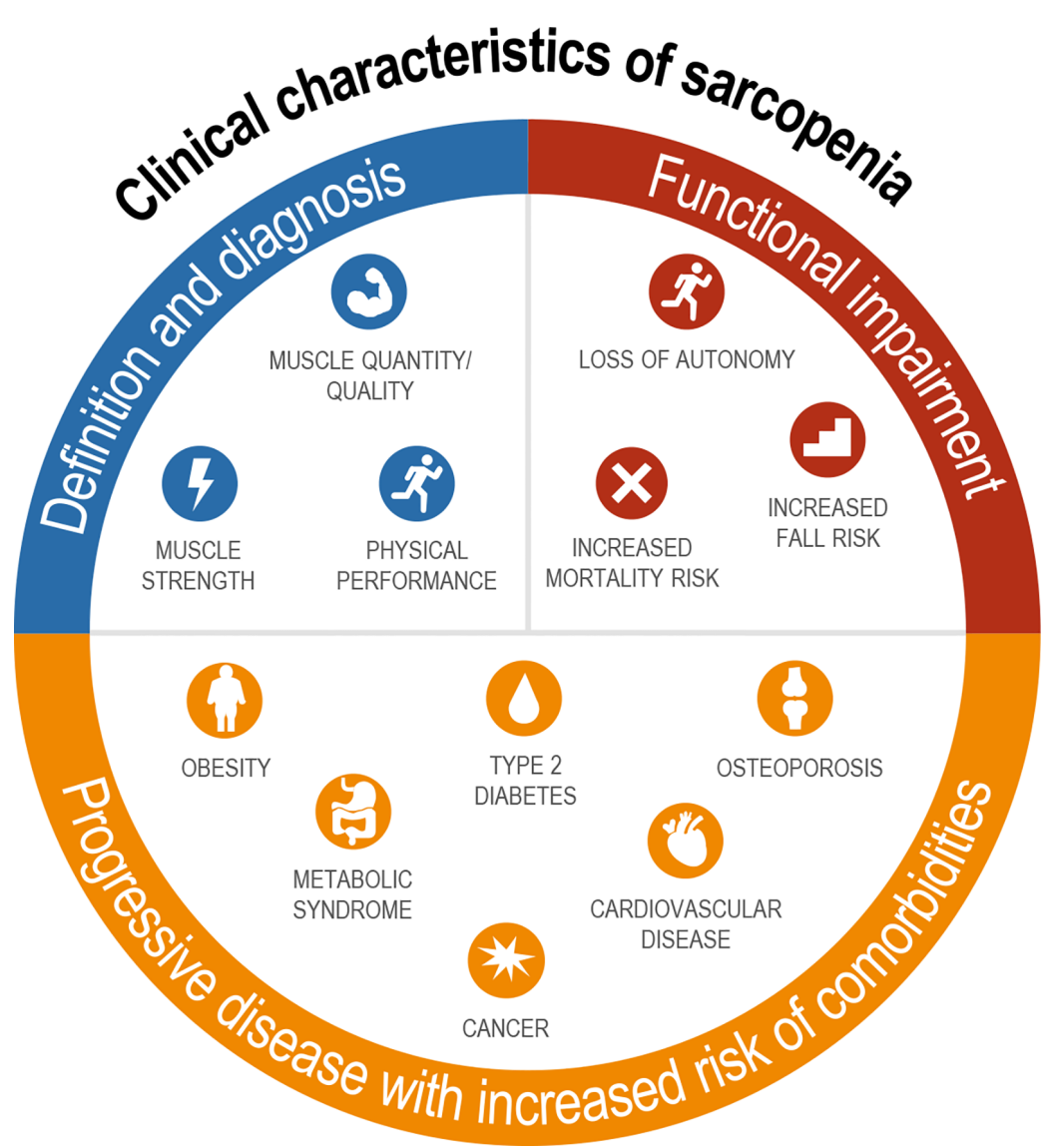

FIGURE 1 | Definition, sequelae, and related comorbidities of sarcopenia. Diagnosis includes assessment of both muscle mass and strength with functional impairments seen across multiple domains; sarcopenia is associated with nearly every major chronic disease.

\section{CLINICAL EVIDENCE LINKING SARCOPENIA AND NON-ALCOHOLIC FATTY LIVER DISEASE/NON-ALCOHOLIC STEATOHEPATITIS}

\section{Meta-Analyses}

Four large meta-analyses ( $N$ ranging from 3,000 to $\sim 30,000$ ) estimated that individuals with sarcopenia were at $\sim 1.3$ - to $1.5-$ fold increased risk of NAFLD compared to those without sarcopenia (41-44). In the few studies that examined the association between sarcopenia and NASH/fibrosis, the odds ratio (OR) for NASH was $\sim 2.4$, and for advanced liver fibrosis the OR ranged from $\sim 1.6$ to $\sim 2.4$ across the various studies $(41,42,44)$. Conversely, skeletal muscle index (SMI) (skeletal muscle mass divided by height squared or weight) in NAFLD patients was $\sim 1.8$-fold lower (95\% CI: 1.15-2.39) than that in healthy controls (42). However, there was generally high heterogeneity among the studies ( $\mathrm{I}^{2}$ range $61 \%-98 \%$ ).

\section{Population-Based Studies}

High-quality population studies have emerged over recent years to explore the relationship between sarcopenia and the presence and severity of $\operatorname{NAFLD}(25,45)$. In studies conducted in Chinese and European individuals, SMI was inversely associated (OR $0.1-0.48$ ), and intramuscular fat was positively associated (OR $\sim 2-10$ ), with NAFLD $(46,47)$. Several cohort and cross-sectional studies have indicated that SMI may be closely associated with the incidence of NAFLD (48-51), and that a low SMI is associated with metabolic dysregulation and NAFLD progression $(52,53)$. Among patients with NAFLD, the presence of sarcopenia was associated with a 2.5 -fold increase in the risk of NASH (52). Advanced liver fibrosis was seen more often in those with sarcopenia $(7.8 \%)$ compared to those without $(1.6 \%)$, and sarcopenia was associated with advanced liver fibrosis (OR 1.8), independent of other metabolic risk factors (54).

The impact of skeletal muscle mass and its changes over time on the development of incident NAFLD or the resolution of baseline NAFLD were studied in a cohort of 12,624 subjects without baseline NAFLD and 2,943 subjects with baseline NAFLD (49). In this study, NAFLD was assessed by hepatic steatosis index, and SMI was estimated by bioimpedance analysis. Over a 7-year follow-up period, $\sim 15 \%$ of the total population without baseline NAFLD developed NAFLD. Increased SMI was associated with reduced incidence of 
NAFLD [adjusted hazard ratio (AHR): 0.84 (95\% CI: 0.79-0.90) per percent increase in SMI over 1 year]. Similarly, participants in the highest tertile of change in SMI over 1 year (compared with the lowest tertile) had both a lower likelihood of incident NAFLD [AHR: 0.69 (95\% CI: 0.59-0.82)] and a higher likelihood of resolution of baseline NAFLD [AHR: 4.17 (95\% CI: 1.906.17)] even after adjustment for multiple covariates, including baseline SMI (Figure 2) (49). Subjects in the highest tertile of change in SMI over 1 year also showed the greatest reductions in BMI, alanine aminotransferase and aspartate aminotransferase, fasting glucose, homeostatic model assessment of insulin resistance, lipid parameters, and hepatic steatosis index score (49). These findings suggest that increases in skeletal muscle mass over time may slow, halt, or reverse NAFLD development and facilitate resolution of existing NAFLD.

In the prospective, observational Korean Sarcopenic Obesity cohort study of 452 apparently healthy adults (25), individuals with lower skeletal muscle mass (as measured by DXA to estimate SMI) exhibited increased risk of NAFLD (defined by the liver attenuation index measured using abdominal CT). In a multiple logistic regression analysis, the OR for NAFLD was 5.16 (95\% CI: 1.63-16.33) in the lowest quartile of SMI compared to the highest quartile after adjusting for age and gender; this association remained independent of insulin resistance (25). A subsequent population-based nationwide survey (Korea National Health and Nutrition Examination Survey 2008-2011) corroborated these findings by demonstrating that sarcopenia was associated with NAFLD independent of obesity and insulin resistance (23). There was also a strong graded response with disease severity for NASH and fibrosis stage, both independent of obesity $(52,55)$.

\section{A Few Limitations of Current Clinical Evidence}

In most of these studies, both skeletal muscle mass and liver fat assessments were based on a variety of methods without a uniform reference standard. The most commonly used techniques were bioelectrical impedance analysis and DXA to estimate muscle mass. Previous studies have shown that both techniques are fraught with accuracy, sensitivity, and reproducibility issues (56-60). Cross sectional imaging (e.g., by CT or MRI) are considered to be gold standards, but do not lend themselves readily to use in large trial settings (61). In addition, while CT is sensitive for detecting moderate to advanced hepatic steatosis, it has limited diagnostic performance to assess mild steatosis (62). In almost all of the population studies, there was limited to no information on function (strength or muscle quality). Most studies used surrogate indices for NASH diagnosis, and only 2 studies used liver biopsy (52, 55). There were also large differences in the populations studied, with Asian populations predominating, and limited evidence from other ethnic groups. Although adjustment for common confounders such as age and gender was usually performed, there was less frequent adjustment for other known confounders such as inflammation and physical activity. Finally, most studies were cross-sectional in nature, complicating attempts to establish a cause-effect relationship.

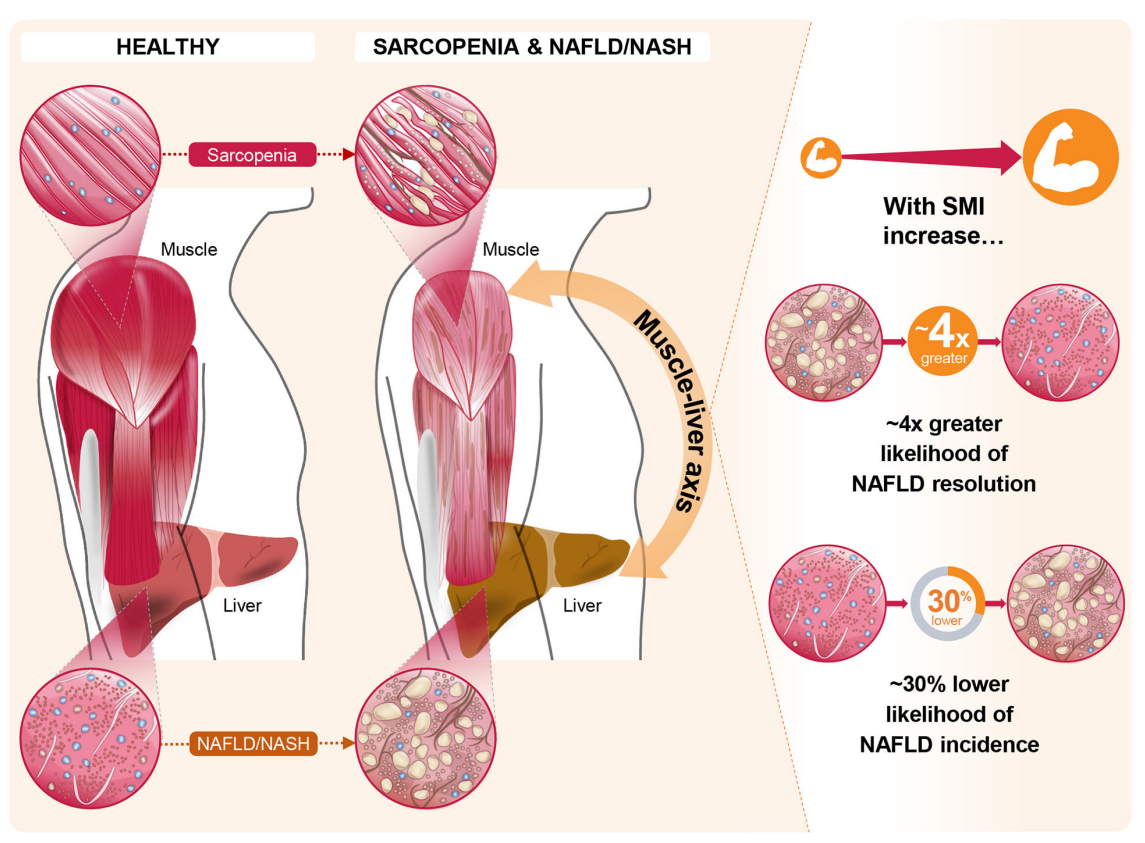

FIGURE 2 | The role of the muscle-liver axis in sarcopenia and non-alcoholic fatty liver disease (NAFLD)/non-alcoholic steatohepatitis (NASH). Recent evidence in the context of NAFLD and NASH, such as that from Kim et al (49). offers compelling associations between changes in skeletal muscle index (SMI) and both NAFLD incidence and resolution of existing NAFLD. In this longitudinal study, these marked associations persisted for the highest tertile of SMI change over 1 year, relative to the lowest tertile, even after full adjustments for multiple covariates including baseline SMI. 


\section{MUSCLE COMPOSITION AND PHYSICAL FUNCTION IN NON-ALCOHOLIC FATTY LIVER DISEASE}

Muscle composition is a major determinant of global muscle metabolic function, strength, and physical performance (63). Detailed measurement of muscle composition includes not only muscle mass, but also quantification of fat-free muscle volume and muscle fat infiltration (myosteatosis) (64). Myosteatosis has been linked to metabolic, functional, and clinical outcomes (65), a higher risk for cirrhosis-related complications such as hepatic encephalopathy (66), and overall mortality in patients with cirrhosis (67). The UK-Biobank (UKBB), a large and detailed prospective study following 500,000 healthy volunteers in the UK, gathered extensive datasets based on physical examinations, blood and urine samples, genetic profiles, patient health-related quality-of-life questionnaires, functional performance measures such as handgrip strength, walking pace, stair climbing, and falls, and health outcomes such as hospitalization and death $(64,68)$. Data from approximately 10,000 UKBB participants demonstrated that muscle composition (based on fat-free muscle volume and myosteatosis by water-fat separated neck-to-knee MRI), even after adjustment for age, gender and BMI, was more strongly associated with physical function, activities of daily living, and hospitalization than muscle volume alone, enabling an objective and improved definition of sarcopenia that is unaffected by body size (64).

Recent evidence shows that muscle composition also plays a significant role in NAFLD and related comorbidities. The UKBB resource was investigated for the impact of MRI-measured adverse muscle composition (AMC), defined as the presence of low muscle volume (i.e., $<25^{\text {th }}$ percentile of the UKBB population) in conjunction with high muscle fat infiltration (i.e., $>75^{\text {th }}$ percentile of the UKBB population) in 1,204 participants (women: 46.4\%; mean age: 62.9 years; mean BMI: $30.1 \mathrm{~kg} / \mathrm{m}^{2}$ ) with NAFLD (defined as MRI-proton density fat fraction, PDFF $>5 \%$ ), and low alcohol consumption (less than 14 and 21 units/week for females and males, respectively) and those without NAFLD ( $n=4,122$; MRI-PDFF $</=5 \%$ with low alcohol consumption). In this study, muscle fat was significantly elevated in those with NAFLD vs. those without ( $8.03 \pm$ $2.08 \%$ vs. $7.21 \pm 1.82 \%$; $p<0.001$ ), and muscle fat infiltration above the 75 th percentile was present in $37.8 \%$ of those 1,204 individuals with NAFLD (69). AMC was found to be highly prevalent, with $14.0 \%$ of the participants with NAFLD having both low muscle volume and high muscle fat (69). In NAFLD subjects, those with AMC as compared to those with low muscle volume alone had a higher prevalence of T2D ( $23.7 \%$ vs. $16.8 \%)$ and coronary heart disease (19.5\% vs. $7.6 \%$ ), as well as poor activities and function of daily living, as indicated by higher prevalence of decreased handgrip strength ( $10.7 \%$ vs. $8.4 \%)$, slow walking pace ( $16.6 \%$ vs. $7.6 \%)$, inability to climb stairs (15.4\% vs. $9.2 \%$ ), and more than one fall in the preceding year (12.4\% vs. 3.4\%) (69) (Figure 3). Interestingly, NAFLD participants presenting with normal muscle composition had similar background metabolic and functional risk as the control (low liver fat and alcohol consumption) population (Figure 3), with the exception of a higher T2D prevalence (69).
The advent of high-precision volumetric measurements in tomographic images such as MRI and CT has also allowed detailed quantification of myosteatosis in those with NAFLD. In a general cohort of 6,021 participants, median muscle fat infiltration was 7.19\% (IQR: 6.18-8.42) (70). In the cohort with NAFLD, muscle fat infiltration in those with normal muscle composition was $6.78 \pm 1.05 \%$, similar to that of the general population; however, in NAFLD subjects with adverse muscle composition, muscle fat content was $10.10 \pm 2.11 \%(\mathrm{p}<0.001)(69)$. The observation of higher myosteatosis in NAFLD subjects is not just restricted to the quadriceps. MRI-based muscle fat infiltration of the spinal erector muscle group (iliocostalis, longissimus, and spinalis) showed an absolute increase of 2.3 percentage points in subjects with NAFLD (10.9\%) as compared to those with other chronic liver diseases (8.6\%), and this number increased further with liver fibrosis stage [absolute increase of 5.0 percentage points in those with F3/F4 (14.9\%) vs. F0 to F2 fibrosis (9.9\%)] (71). Using a CT-based evaluation, another group (72) independently demonstrated higher fat accumulation within the psoas muscle (indicated by $15 \%-20 \%$ lower muscle density) in subjects with NASH with or without fibrosis compared to those with only fatty liver (NAFL); there was no graded response of muscle fat accumulation with fibrosis stage, as NASH subjects with either fibrosis F0/F1 or F2-F4 had similarly decreased muscle density. In a multivariate analysis, only relative muscle density and alanine transaminase emerged as independent predictors of NASH (72). Cumulatively, although these provocative results seem to suggest that myosteatosis by itself could be both a diagnostic and prognostic marker in NAFLD, additional prospective studies would be needed to confirm these initial observations. It also remains to be determined if there is a differential metabolic response to muscle composition changes within peripheral (thigh) and central (spinal erector) muscle groups.

Taken together, abnormal muscle composition in NAFLD, namely low mass with increased myosteatosis, was independently associated with low physical function and was largely underdiagnosed (69). These findings suggest that highly vulnerable populations may not be detected using current sarcopenia measurement tools and that more advanced imaging may help to identify those at risk of impaired physical function (64). Although low muscle volume alone confers greater risk of functional disability in those with NAFLD as compared to age-, gender-, and BMImatched controls, the current evidence suggests that the presence of both low muscle volume and high muscle fat may amplify this risk (Figure 3). Thus, assessing muscle composition in NAFLD using a non-ionizing radiation technique such as MRI that can reliably and reproducibly assess longitudinal changes in muscle composition over time (test-retest repeatability coefficient was 0.53 percentage points for muscle fat infiltration) (73), enables its utilization in clinical trial settings to more robustly characterize both pathophysiology and prognosis: the ability to differentiate between vulnerable and normal sub-groups would aid in selecting a more appropriate (and homogenous) NAFLD population for clinical trials, and in tailoring appropriate therapeutic interventions. The availability of objective and highly reliable biomarkers of overall body composition, including muscle quantity and quality 

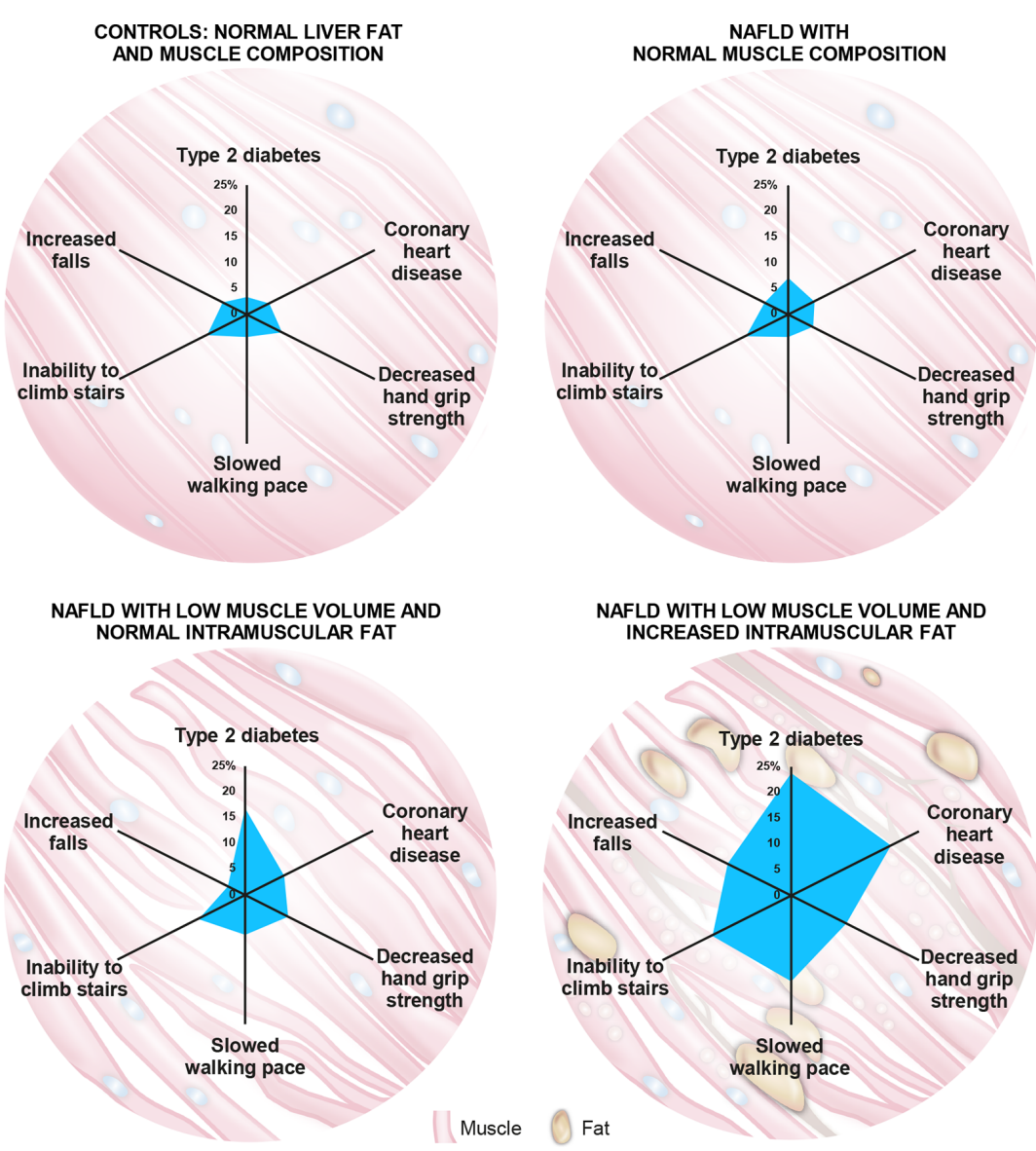

FIGURE 3 | The role of muscle composition in non-alcoholic fatty liver disease (NAFLD) and related comorbidities. A recent analysis of the UK-BioBank (UKBB) resource by Linge et al (69). revealed that participants with NAFLD and normal muscle composition had generally similar metabolic and functional characteristics to those with normal liver and muscle composition. Interestingly, participants with NAFLD combined with adverse muscle composition (AMC), defined as the presence of both low muscle volume (i.e., <25th percentile of the UKBB population) and high muscle fat infiltration (i.e., >75th percentile of the UKBB population), exhibited a larger "footprint" (higher prevalence) of relevant comorbidities and functional impairment when compared with the other groups evaluated. Numbers on axes represent prevalence (\%) of each indicated comorbidity/functional impairment.

(73), would also enable tracking of muscle health, sarcopenic processes, and comorbidities at a much earlier stage and before onset of physical dysfunction. With proper adjustment for body size, these biomarkers avoid known confounding factors unrelated to muscle health or patient fitness (70).

\section{KEY MECHANISMS AND MOLECULAR FACTORS AT THE NEXUS OF NON- ALCOHOLIC FATTY LIVER DISEASE/NON- ALCOHOLIC STEATOHEPATITIS AND SARCOPENIA}

\section{Muscle-Liver Axis}

The relationship between ESLD and sarcopenia is well established $(66,74,75)$. Recent studies, as summarized in Section 2, also highlight an important association between sarcopenia and NAFLD, even among patients who have not yet progressed to ESLD, highlighting the central role of the muscle-liver axis. NAFLD is considered both as a precursor of the metabolic syndrome (76) and as the hepatic manifestation of the metabolic syndrome (77), and therefore likely shares common key mechanisms that link sarcopenia and the metabolic syndrome. Interorgan crosstalk between muscle and liver is influenced by several factors, including underlying obesity, low physical activity, vitamin D deficiency, oxidative stress, a proinflammatory milieu, and insulin resistance. Lipotoxicity induced by fatty acid (FA) overload can also lead to ectopic fat deposition in multiple organs, including liver (hepatic steatosis) and skeletal muscle (myosteatosis), and is likely mediated by hepatokines and myokines (Figure 4) $(78,79)$. In this sense, skeletal muscle could play a causative role in NAFLD through dysregulated secretion of various myokines against the background of sarcopenia. Figure 4 summarizes the proposed mechanisms linking sarcopenia and NAFLD/NASH. 


\section{Key Mechanisms}

\section{Anabolic Resistance}

Dysregulated nitrogen homeostasis underpins impaired hepatic metabolism (80), whereby an imbalance between muscle protein synthesis and muscle protein breakdown ultimately contributes to the decreased muscle mass that accompanies liver disease (81). Protein synthesis in skeletal muscle is activated by anabolic factors such as amino acids (AAs), hormones (insulin, growth hormone, and insulin-like growth factor 1), and mechanical stimulus (muscle contraction) (82). In contrast, protein catabolism is activated by energy deficiency and systemic inflammatory processes (83). Thus, maintenance of muscle mass requires that skeletal muscles are responsive to AA provision, hormonal stimulation, and/or muscle contraction. Consequently, anabolic resistance, the inability of an anabolic stimulus to provide adequate stimulation of muscle protein synthesis, could constitute a key unifying mechanism for the muscle mass loss commonly seen in the setting of NAFLD (Figure 4).

In the fasted state, protein balance is negative since protein synthesis falls below protein catabolism. In contrast, after a meal, protein balance normally becomes positive as protein synthesis increases and proteolysis diminishes, particularly if the meal is high in protein. In the setting of disease (such as NASH, cirrhosis, and post-liver transplantation) or aging, the ability to synthesize protein in response to various nutritional factors (dietary protein, AAs, and insulin) appears to be blunted (82). The result is a negative protein balance with a steady and progressive decline in protein stores. Furthermore, optimal activation of protein synthesis after a meal also depends on the availability of specific signaling AAs $(84,85)$ such as leucine [via its potent activation of mammalian target of rapamycin (mTOR) complex 1] (86) and arginine (via its synthesis of nitric oxide to increase muscle blood flow for substrate supply) (87). Taken together, anabolic resistance may be attributed to inadequate AA availability/delivery, insulin resistance, and/or systemic inflammation, all of which may be further exacerbated in obese older adults.

By taking a rational approach to provide an optimal AA composition, these defects could potentially be overcome. As one example, in a study of prefrail (but not malnourished) subjects with compensated cirrhosis (Child-Pugh Class A and B) largely due to NASH, a defined composition of 8 AAs (leucine, isoleucine, valine, histidine, lysine, threonine, ornithine, and aspartate) in specific ratios (AXA1665; Axcella Health Inc., Cambridge, MA) resulted in leaner body composition (higher \%

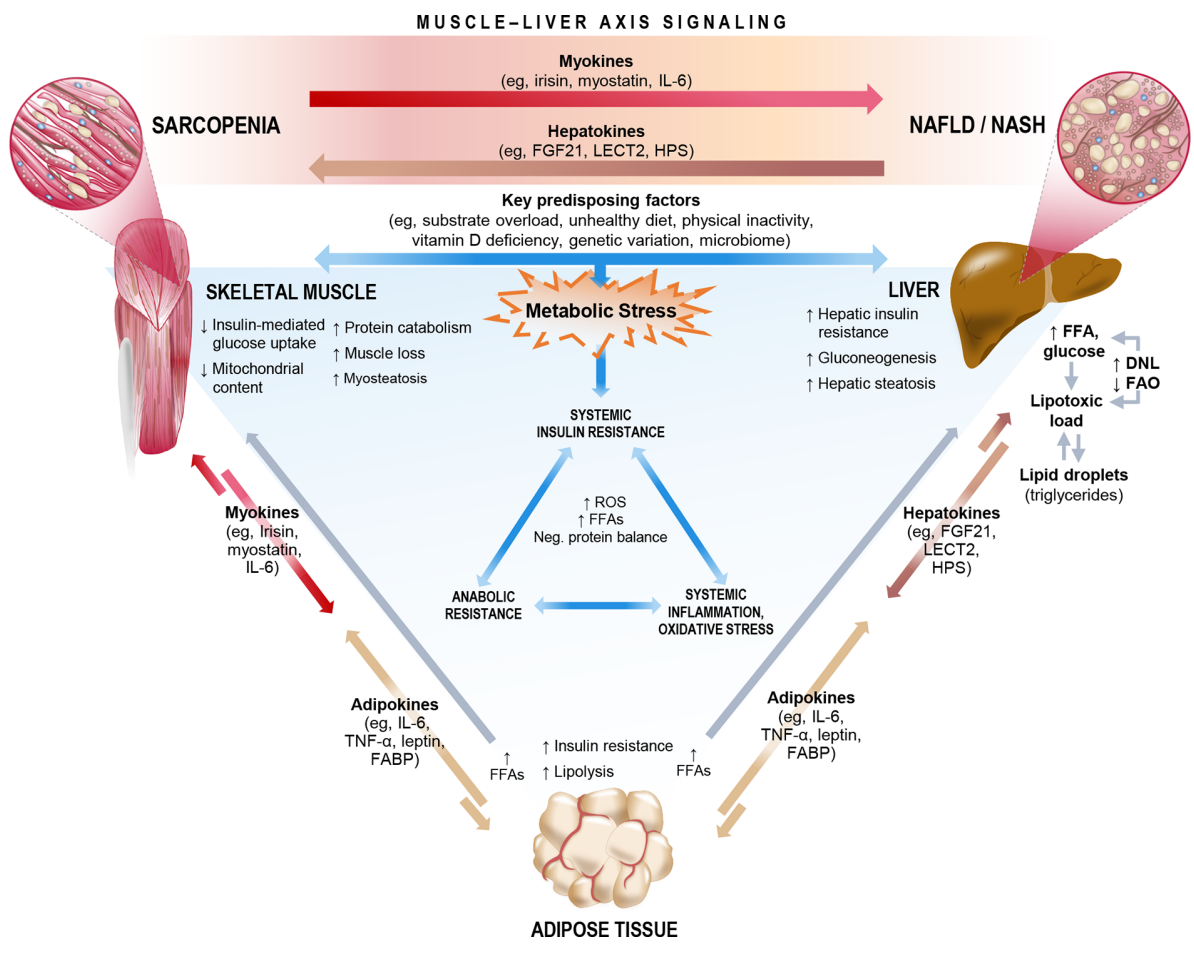

FIGURE 4 | Key mechanisms and molecular signals that link sarcopenia and non-alcoholic fatty liver disease (NAFLD)/non-alcoholic steatohepatitis (NASH). The complex interorgan crosstalk between liver and muscle likely shares a number of key underlying mechanisms, many of which relate both sarcopenia and NAFLD/NASH to metabolic stress, cascading to biochemical pathways that impact systemic insulin resistance, inflammation/oxidative stress, and anabolic resistance. Among these mechanisms are a number of existing or emergent predisposing factors and the release of multidirectional molecular signals consisting of myokines, hepatokines, and adipokines. In the context of sarcopenia, skeletal muscle could exert dysregulated influence on the muscle-liver axis to potentially play a causative role in NAFLD incidence or progression. DNL, de novo lipogenesis; FABP, fatty acid-binding protein; FAO, fatty acid oxidation; FFA, free fatty acid; FGF21, fibroblast growth factor 21; HPS, hepassocin; IL-6, interleukin-6; LECT2, leukocyte cell-derived chemotaxin-2; ROS, reactive oxygen species; TNF- $\alpha$, tumor necrosis factor-alpha. 
lean mass with lower $\%$ body fat mass) coupled with significant improvement in the Liver Frailty Index, a composite physical function assessment of handgrip strength, timed chair stands, and balance (88). Anabolic resistance may also be overcome with exercise. In an individualized web-based exercise program that combined endurance and strength training with bidirectional feedback carried out over 8 weeks in a prescribed sequence to stimulate muscular strength in patients with histologically confirmed NASH, improvements in markers of steatosis (decreased fatty liver index), fibrogenesis (decreased ProC3) and fibrinolysis (increased C4M2) were demonstrated (89). Together, such interventional studies suggest that modulation of muscle physiology to overcome anabolic resistance could be a core pathway to impact body composition, physical function, and hepatic fibrosis remodeling in subjects with NASH.

\section{Insulin Resistance}

Skeletal muscle is the principal organ in energy metabolism and is responsible for insulin-mediated glucose uptake, which occurs via glucose transporter 4 . Animal models with muscle-specific glucose transporter 4 knockouts develop severe insulin resistance (90). In addition to stimulating uptake of glucose, insulin also enhances protein synthesis, inhibits proteolysis, and stimulates AA transport in skeletal muscle $(91,92)$. Insulin also increases the supply of nutrients to muscles through its vasodilatory properties and, consequently, plays an important role in the physiological coupling between hemodynamic and metabolic homeostasis (93). Insulin, via its activation of p38 mitogenactivated protein kinase (MAPK) and mTOR, stimulates mRNA translation of genes responsible for muscle proliferation and hypertrophy (94). These effects of insulin on muscle are blunted in the state of insulin resistance, and could lead to anabolic resistance, characterized by reduced protein synthesis and reduced insulin-mediated suppression of protein catabolism (95-97). Impaired insulin-stimulated glucose uptake into muscle leads to further deterioration of whole-body glucose homeostasis and worsening sarcopenia. Thus, insulin resistance, which is also an underlying driver of NAFLD pathogenesis $(98,99)$, directly links NAFLD and sarcopenia (Figure 4).

In NAFLD, weight gain is associated with visceral adipose tissue expansion and infiltration of adipose tissue by macrophages and adipose tissue inflammation (100). This local inflammatory milieu promotes development of insulin resistance at the level of adipose tissue (101). Furthermore, insulin and other effectors of skeletal muscle anabolism (i.e., resistance exercise and essential AAs) are less effective at inducing skeletal muscle protein synthesis in the presence of increased adiposity (102, 103). Thus, loss of muscle mass can lead to significant whole-body metabolic disturbances that include decline in basal metabolic rate, and loss of mitochondrial volume, density, and oxidative capacity, with further exacerbation of muscle loss (Figure 4) (104, 105). Conversely, improving skeletal muscle oxidative capacity as exemplified by exercise training (both resistance and aerobic training) has been shown to significantly reduce intrahepatic fat content independent of weight loss in subjects with fatty liver and type 2 diabetes $(106,107)$.

Normal energy metabolism is characterized by periodic shifts between glucose and FA oxidation depending on fuel availability (108). Skeletal muscle is a major contributor to whole-body energy expenditure and thus is a key organ in energy homeostasis (7). The ability to preferentially use the appropriate fuel substrates (i.e., FAs during fasting and carbohydrate in fed states) for energy generation is referred to as metabolic flexibility (109). In the normal fasted state, serum insulin levels decrease, thereby releasing insulin-mediated suppression of lipolysis of adipose tissue. This results in a steady supply of FAs to be used as the major fuel source during fasting (110). In the postprandial state, meal-induced insulin secretion facilitates the transport of glucose into intracellular compartments, where it is used as the preferred fuel source. When the body is unable to preferentially utilize the appropriate fuel sources at the appropriate energy state, the result is metabolic inflexibility, which is associated with weight gain, diabetes, and NASH $(1,111-113)$.

In a metabolically inflexible state, normal pulsatile insulin release in response to the level of satiety is impaired such that basal insulin levels remain high even in the fasted state (109). Despite hyperinsulinemia, insulin resistance at the level of adipose tissue results in adipose tissue lipolysis, and increased generation of circulating FAs that are not utilized for oxidation (114). Thus, a hallmark of metabolic inflexibility is the impaired ability of skeletal muscle both to oxidize FAs in the fasted state and to switch to carbohydrate utilization in the fed or insulin stimulated state (115). This concept was recently demonstrated using whole-room calorimetry with continuous 18-hour monitoring in a cohort of patients undergoing liver transplantation for NASH- and non-NASH-related cirrhosis (116). The cellular rate of carbon dioxide production relative to oxygen consumption [respiratory quotient (RQ)] is used to quantify whole-body fuel utilization: an RQ value of 0.7 is indicative of pure FA oxidation, whereas an RQ of 1.0 is indicative of pure carbohydrate oxidation. After a standardized meal, patients undergoing transplantation for NASH-related cirrhosis took longer to switch to carbohydrate metabolism than those with non-NASH-related cirrhosis (514 vs. $430 \mathrm{~min}$; $p=0.03$ ), indicating less efficient biofuel switching in the fed state (Figure 5). Patients from both cohorts had similar peak RQ values, indicating that although it took patients with NASHrelated cirrhosis longer to switch to carbohydrate metabolism, they were still able to reach the same magnitude of carbohydrate metabolism as patients with non-NASH-related cirrhosis. Similarly, in the fasted state, patients with NASH-related cirrhosis took longer to reach the lowest RQ, again reflecting less efficient switching of biofuel utilization toward fat oxidation (Figure 5). Finally, patients with NASH-related cirrhosis had significantly higher RQ values even during prolonged fasting, indicating continued reliance on carbohydrates, even under low carbohydrate conditions (Figure 5). Due to the impaired ability to oxidize FAs in this metabolically inflexible state, excess FAs 
are stored within the muscle leading to accumulation of intramyocellular lipid (myosteatosis). This relationship was also confirmed in the above-mentioned study, where an inverse relationship between myosteatosis and metabolic flexibility was demonstrated (116). Furthermore, myosteatosis has been associated with reduced muscle protein synthesis, linking insulin resistance to sarcopenia (117).

\section{Systemic Inflammation}

Recent studies recognize both NAFLD and obesity as subclinical inflammatory states $(118,119)$. Indeed, metabolic inflammation emanating from the fatty liver is postulated as a key driver of downstream cellular dysfunction, cell death, and deleterious remodeling within various body tissues, possibly including skeletal muscle (120). In obesity, increased adipose tissue secretes adipokines and other proinflammatory cytokines (Figure 4), which promote infiltration of inflammatory cells, including macrophages (100). The infiltrating macrophages change their phenotype from M2 to M1 and release proinflammatory cytokines such as interleukin (IL)-6, tumor necrosis factor (TNF)- $\alpha$, and IL-1 $\beta(121,122)$. These cytokines negatively impact skeletal muscle by upregulating proteasomal decay of filament proteins and promoting apoptosis (123). Incremental release of IL- 6 under normal physiological conditions (e.g., muscle contractile activity) improves insulin signaling by enhancing glucose uptake and increasing FA oxidation in myocytes via phosphoinositide 3-kinase (PI3K) and AMP-activated protein kinase (AMPK) (124), while also inducing anti-inflammatory cytokines (i.e., IL-10) (125). However, in chronic inflammatory states such as those that may occur in obesity and NAFLD, IL- 6 acts as a proinflammatory cytokine, reducing myogenesis by inhibiting insulin-like growth factor (IGF)-1 activity via activation of suppressor of cytokine signaling-3 (SOCS-3) $(126,127)$.

\section{Other Key Molecular Factors}

Other reviews have extensively covered molecular mediators underlying both sarcopenia and NAFLD $(78,128,129)$. Here, we focus primarily on three key factors that can significantly influence muscle-liver crosstalk by modulating glucose homeostasis and insulin resistance to impact NAFLD pathogenesis and disease progression.

\section{Myostatin}

Myostatin is a well-established myokine that plays a central role in inhibiting skeletal muscle growth and mass (130). In patients with ESLD, four-fold elevated serum myostatin levels are reported (131). Myostatin has both local and endocrine effects that can link sarcopenia and NAFLD via a complex signal transduction process involving downregulation of genes controlling myogenesis and muscle protein synthesis, while simultaneously activating proteasome-ubiquitin ligases (132). Metabolically, myostatin regulates glucose disposal and adiposity, including increased browning of adipose tissue (133). Deletion of myostatin in mouse models produces dramatic improvements in insulin sensitivity and glucose uptake, and a reduction in adiposity (134). Inactivation or absence of functional myostatin increased lipolysis and FA oxidation in peripheral tissues, increased muscle mass $(135,136)$, and ameliorated fatty liver in mice (137). Although the exact mechanism is not entirely clear, a myostatin receptor has been reported on hepatic stellate cells (138, 139). It has recently been demonstrated that myostatin reduced human stellate cell proliferation, induced cell migration, and increased expression of procollagen type 1, tissue inhibitor of

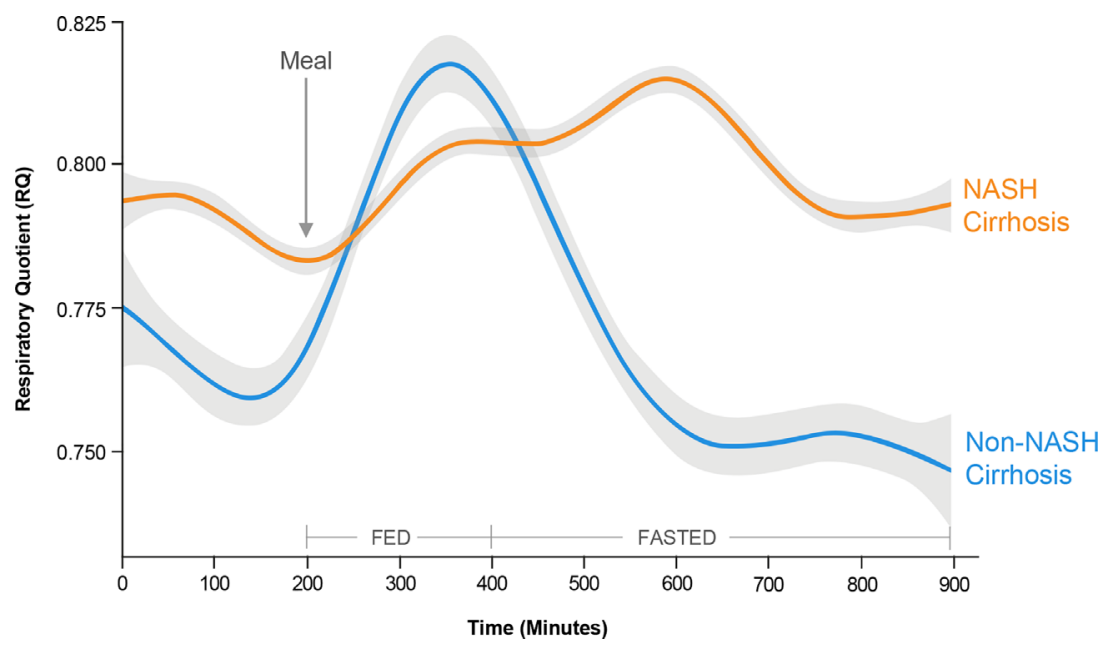

FIGURE 5 | Metabolic inflexibility in non-alcoholic steatohepatitis (NASH). Continuous respiratory quotient (RQ) evaluations in a whole-room calorimetry study revealed less efficient biofuel switching, i.e., metabolic inflexibility, among subjects with NASH cirrhosis compared with non-NASH cirrhosis, manifesting as a delayed time to peak $R Q$ in a fed state, and an inability to switch to lower $R Q$ in a fasted state. These findings reflect an impaired ability of skeletal muscle to utilize fatty acids for oxidation in the fasted state in subjects with NASH cirrhosis. [Adapted from Siddiqui et al (116). Copyright 2019, with permission from Wiley.]. 
metalloproteinase-1, and transforming growth factor- $\beta 1$ (139), further implicating myostatin as a key molecular mediator of muscle-liver crosstalk.

\section{Irisin}

Insulin resistance also impacts the myokine profile of skeletal muscle, promoting impaired skeletal muscle growth and proliferation. Irisin, a myokine, acts on skeletal muscle, resulting in increased energy expenditure and oxidative metabolism via regulation of cellular energetics $(140,141)$ and is a critical mediator of hepatic glucose and lipid metabolism (142). Irisin expression in skeletal muscle is reduced in obesity and is related to insulin sensitivity (143). Irisin improves glucose homeostasis, increases adipocyte energy expenditure, and modulates the expression of enzymes that inhibit lipid accumulation and reduces weight $(144,145)$. In adipocytes, irisin promotes differentiation of white adipose tissue to brown adipocytes, thereby underscoring the beneficial pleiotropic effects of irisin in improving adipocyte metabolism (140). Thus, it is plausible that decreased skeletal muscle could be a causative factor of NAFLD incidence due to reduced secretion of various salutary myokines.

\section{Vitamin D}

Vitamin D deficiency has been implicated as a potential contributor to both muscle- and liver-related metabolic derangements (146). Vitamin D regulates expression of insulin receptors in pancreatic $\beta$-cells $(147,148)$ and peripheral target tissues (149). Vitamin D receptor is expressed within the liver (150) and may mediate hepatic injury via modulation of systemic inflammation and oxidative stress (151). Clinically, patients with NAFLD have lower levels of vitamin D (152). Furthermore, vitamin $\mathrm{D}$ receptor expression on hepatocytes inversely correlates with severity of liver disease, while accounting for traditional metabolic risk factors (153). In the Longitudinal Aging Study Amsterdam, vitamin D deficiency (25hydroxyvitamin $\mathrm{D}$ level $<25 \mathrm{nmol} / \mathrm{L}$ at baseline) was associated with 2.1- and 2.6-fold increased risk of low appendicular muscle mass and grip strength, respectively, during a 3-year follow-up period (154). Muscle-specific vitamin D receptor knockout mice have reduced muscle size, impaired motor activity, and abnormal muscle development $(155,156)$. Vitamin D deficiency also adversely affected skeletal muscle insulin sensitivity, thereby contributing to reduced metabolic flexibility (157). Taken together, these data indicate that vitamin $\mathrm{D}$ deficiency and/or its impaired signaling is a critical mediator at the nexus of NAFLD and sarcopenia. Data to support the critical role of vitamin $\mathrm{D}$ in directly improving muscle strength and function is provided from several large placebo-controlled randomized controlled trials (RCTs) that demonstrated the effect of vitamin D supplementation on increasing quadriceps strength $(158,159)$, improving mobility in 6 minute walk (160), jump velocity (161), timed-up-and go (159) tests, and in reducing the incidence of falls (162). Two large meta-analyses which pooled results from 13 RCTs in $>60$-year-old subjects (163) and another that pooled 17 RCTs in all age groups, including younger subjects (164), suggested that daily vitamin D supplementation (800 IU to 1000
IU per day) was beneficial for muscle strength and balance, especially in those with a baseline serum vitamin $\mathrm{D}$ level $<25$ $\mathrm{nmol} / \mathrm{L}$.

\section{SUMMARY AND FUTURE DIRECTIONS}

Multiple factors have been delineated in the pathogenesis of NAFLD/NASH, including immune regulation, lipolysis, leaky gut and bile acid homeostasis, among others. There is close overlap between the pathophysiology of sarcopenia and NASH. This makes it challenging to determine whether sarcopenia is a risk factor for $\mathrm{NASH}$, or if it is a complication of NASH, as the presence of either one may increase the risk for the other. Nonetheless, the current data squarely place skeletal muscle, insulin resistance, and inflammation in the center of the NAFLD/NASH pathogenic cascade. Sarcopenia is widely prevalent and appears to be an effect modifier across the NAFLD spectrum-NAFL, NASH, and fibrosis. Emerging data suggest that it could also potentially be a "causative" factor, although additional studies are needed. Body composition can provide additional insight into the understanding of NAFLD. Interventions that can impact muscle composition, while simultaneously engaging multiple targets/pathways in the muscle-liver axis, would need to be considered to adequately address the complex multifactorial pathogenesis of NAFLD/ $\mathrm{NASH}$, and consequently achieve highly effective and durable therapies.

Toward that end, there is a need for deeper understanding of the biology of sarcopenia and its impact on NAFLD. For example, which component of muscle (fat-free muscle volume, or intramuscular fat, or both) impacts more on NAFLD progression and on clinical outcomes? Does myosteatosis still drive NAFLD after adjustment of visceral adiposity? Additional studies are also warranted to better understand various clinical assessment tools, including the prognostic impact of how strength is measured, since handgrip and chair-stand involve two distinct muscle groups, and some of the physical performance test measures are closely related to cardiopulmonary fitness. Dissecting these aspects would be critical to bring forward future individualized recommendations on when to use one test versus the other, which patients differ strongly in hand grip versus chair-stand test, how large is the overlap, and consequently, identify relevant confounders with regard to NAFLD. There is also a need to validate the definitions and cutoff values for muscle mass and function endpoints in clinical trials, which could inform on how to stratify patients in interventional studies, thereby providing better understanding of the magnitude and relevant thresholds of change in those measures associated with clinically meaningful outcomes. Finally, establishing experimental models of sarcopenia and fatty liver disease to elucidate a direct causeeffect relationship between muscle mass and liver lipids would be helpful. Routine measurements of muscle composition and function should also be considered in controlled prospective interventional NASH trials to establish cause-effect relationships in the clinical setting with adjustment for confounding factors 
such as obesity, physical activity, and inflammation that can influence clinical outcomes.

\section{AUTHOR CONTRIBUTIONS}

MC conceived, authored the initial draft of the manuscript, and developed the figure concepts. MS, MF, and AS provided further content, added key references, and authored sections of the manuscript. All authors contributed to the article and approved the submitted version.

\section{REFERENCES}

1. Chakravarthy MV, Neuschwander-Tetri BA. The metabolic basis of nonalcoholic steatohepatitis. Endocrinol Diabetes Metab (2020) 3(4): e00112. doi: 10.1002/edm2.112

2. Friedman SL, Neuschwander-Tetri BA, Rinella M, Sanyal AJ. Mechanisms of NAFLD development and therapeutic strategies. Nat Med (2018) 24:90822. doi: 10.1038/s41591-018-0104-9

3. Konerman MA, Jones JC, Harrison SA. Pharmacotherapy for NASH: Current and emerging. J Hepatol (2018) 68:362-75. doi: 10.1016/ j.jhep.2017.10.015

4. Wegermann K, Diehl AM, Moylan CA. Disease pathways and molecular mechanisms of nonalcoholic steatohepatitis. Clin Liver Dis (Hoboken) (2018) 11:87-91. doi: 10.1002/cld.709

5. Noureddin M, Muthiah MD, Sanyal AJ. Drug discovery and treatment paradigms in nonalcoholic steatohepatitis. Endocrinol Diabetes Metab (2019) 3(4):e00105. doi: 10.1002/edm2.105

6. DeFronzo RA, Tripathy D. Skeletal muscle insulin resistance is the primary defect in type 2 diabetes. Diabetes Care (2009) 32 Suppl 2:S157-63. doi: $10.2337 / \mathrm{dc09}-\$ 302$

7. Zurlo F, Larson K, Bogardus C, Ravussin E. Skeletal muscle metabolism is a major determinant of resting energy expenditure. J Clin Invest (1990) 86:1423-7. doi: $10.1172 /$ jcil14857

8. Neuschwander-Tetri BA. Non-alcoholic fatty liver disease. BMC Med (2017) 15:45. doi: 10.1186/s12916-017-0806-8

9. Bhupathiraju SN, Hu FB. Epidemiology of obesity and diabetes and their cardiovascular complications. Circ Res (2016) 118:1723-35. doi: 10.1161/ circresaha.115.306825

10. Gastaldelli A, Cusi K. From NASH to diabetes and from diabetes to NASH: mechanisms and treatment options. JHEP Rep (2019) 1:312-28. doi: 10.1016/j.jhepr.2019.07.002

11. Younossi ZM, Koenig AB, Abdelatif D, Fazel Y, Henry L, Wymer M. Global epidemiology of nonalcoholic fatty liver disease - meta-analytic assessment of prevalence, incidence, and outcomes. Hepatology (2016) 64:73-84. doi: $10.1002 /$ hep. 28431

12. Younossi ZM. The epidemiology of nonalcoholic steatohepatitis. Clin Liver Dis (Hoboken) (2018) 11:92-4. doi: 10.1002/cld.710

13. Younossi ZM, Golabi P, de Avila L, Paik JM, Srishord M, Fukui N, et al. The global epidemiology of NAFLD and NASH in patients with type 2 diabetes: a systematic review and meta-analysis. J Hepatol (2019) 71:793-801. doi: 10.1016/j.jhep.2019.06.021

14. Younossi Z, Anstee QM, Marietti M, Hardy T, Henry L, Eslam M, et al. Global burden of NAFLD and NASH: trends, predictions, risk factors and prevention. Nat Rev Gastroenterol Hepatol (2018) 15:11-20. doi: 10.1038/ nrgastro.2017.109

15. Sayiner M, Koenig A, Henry L, Younossi ZM. Epidemiology of nonalcoholic fatty liver disease and nonalcoholic steatohepatitis in the United States and the rest of the world. Clin Liver Dis (2016) 20:205-14. doi: 10.1016/ j.cld.2015.10.001

16. Goldberg D, Ditah IC, Saeian K, Lalehzari M, Aronsohn A, Gorospe EC, et al. Changes in the prevalence of hepatitis $\mathrm{C}$ virus infection, nonalcoholic steatohepatitis, and alcoholic liver disease among patients with cirrhosis or

\section{FUNDING}

This support was funded by Axcella Health Inc.

\section{ACKNOWLEDGMENTS}

Editorial and graphical assistance were provided to the authors by Andrew Fitton and Michelle Kwon of Evidence Scientific Solutions, Inc (Philadelphia, PA).

liver failure on the waitlist for liver transplantation. Gastroenterology (2017) 152:1090-9. doi: 10.1053/j.gastro.2017.01.003

17. Wong RJ, Aguilar M, Cheung R, Perumpail RB, Harrison SA, Younossi ZM, et al. Nonalcoholic steatohepatitis is the second leading etiology of liver disease among adults awaiting liver transplantation in the United States. Gastroenterology (2015) 148:547-55. doi: 10.1053/j.gastro.2014.11.039

18. GBD 2017 Cirrhosis Collaborators. The global, regional, and national burden of cirrhosis by cause in 195 countries and territories, 1990-2017: a systematic analysis for the Global Burden of Disease Study 2017. Lancet Gastroenterol Hepatol (2020) 5:245-66. doi: 10.1016/s2468-1253(19)30349-8

19. Polyzos SA, Kountouras J, Mantzoros CS. Obesity and nonalcoholic fatty liver disease: From pathophysiology to therapeutics. Metabolism (2019) 92:82-97. doi: 10.1016/j.metabol.2018.11.014

20. Sinclair M, Gow PJ, Grossmann M, Angus PW. Review article: sarcopenia in cirrhosis-aetiology, implications and potential therapeutic interventions. Aliment Pharmacol Ther (2016) 43:765-77. doi: 10.1111/apt.13549

21. Roh E, Choi KM. Health consequences of sarcopenic obesity: a narrative review. Front Endocrinol (Lausanne) (2020) 11:332. doi: 10.3389/fendo.2020.00332

22. Lee YH, Kim SU, Song K, Park JY, Kim DY, Ahn SH, et al. Sarcopenia is associated with significant liver fibrosis independently of obesity and insulin resistance in nonalcoholic fatty liver disease: Nationwide surveys (KNHANES 2008-2011). Hepatology (2016) 63:776-86. doi: 10.1002/ hep. 28376

23. Lee Y-H, Jung KS, Kim SU, Yoon H-J, Yun YJ, Lee B-W, et al. Sarcopaenia is associated with NAFLD independently of obesity and insulin resistance: nationwide surveys (KNHANES 2008-2011). J Hepatol (2015) 63:486-93. doi: 10.1016/j.jhep.2015.02.051

24. Rosenberg IH. Summary comments. Am J Clin Nutr (1989) 50:1231-3. doi: 10.1093/ajen/50.5.1231

25. Hong HC, Hwang SY, Choi HY, Yoo HJ, Seo JA, Kim SG, et al. Relationship between sarcopenia and nonalcoholic fatty liver disease: The Korean Sarcopenic Obesity Study. Hepatology (2014) 59:1772-8. doi: 10.1002/hep.26716

26. Cruz-Jentoft AJ, Bahat G, Bauer J, Boirie Y, Bruyère $O$, Cederholm T, et al. Sarcopenia: revised European consensus on definition and diagnosis. Age Ageing (2019) 48:16-31. doi: 10.1093/ageing/afy169

27. Nachit M, Leclercq IA. Emerging awareness on the importance of skeletal muscle in liver diseases: time to dig deeper into mechanisms! Clin Sci (Lond) (2019) 133:465-81. doi: 10.1042/CS20180421

28. Janssen I, Heymsfield SB, Ross R. Low relative skeletal muscle mass (sarcopenia) in older persons is associated with functional impairment and physical disability. J Am Geriatr Soc (2002) 50:889-96. doi: 10.1046/ j.1532-5415.2002.50216.x

29. Wang C, Bai L. Sarcopenia in the elderly: basic and clinical issues. Geriatr Gerontol Int (2012) 12:388-96. doi: 10.1111/j.1447-0594.2012.00851.x

30. Walston JD. Sarcopenia in older adults. Curr Opin Rheumatol (2012) 24:623-7. doi: 10.1097/BOR.0b013e328358d59b

31. Siparsky PN, Kirkendall DT, Garrett WEJr. Muscle changes in aging: understanding sarcopenia. Sports Health (2014) 6:36-40. doi: 10.1177/ 1941738113502296

32. Batsis JA, Villareal DT. Sarcopenic obesity in older adults: aetiology, epidemiology and treatment strategies. Nat Rev Endocrinol (2018) 14:51337. doi: 10.1038/s41574-018-0062-9 
33. Dunne RF, Loh KP, Williams GR, Jatoi A, Mustian KM, Mohile SG. Cachexia and sarcopenia in older adults with cancer: a comprehensive review. Cancers (Basel) (2019) 11:1861. doi: 10.3390/cancers11121861

34. Farmer RE, Mathur R, Schmidt AF, Bhaskaran K, Fatemifar G, Eastwood SV, et al. Associations between measures of sarcopenic obesity and risk of cardiovascular disease and mortality: a cohort study and mendelian randomization analysis using the UK Biobank. J Am Heart Assoc (2019) 8: e011638-e. doi: 10.1161/JAHA.118.011638

35. Mesinovic J, Zengin A, De Courten B, Ebeling PR, Scott D. Sarcopenia and type 2 diabetes mellitus: a bidirectional relationship. Diabetes Metab Syndr Obes (2019) 12:1057-72. doi: 10.2147/DMSO.S186600

36. Park S-J, Ryu S-Y, Park J, Choi S-W. Association of sarcopenia with metabolic syndrome in Korean population using 2009-2010 Korea National Health and Nutrition Examination Survey. Metab Syndr Relat Disord (2019) 17:494-9. doi: 10.1089/met.2019.0059

37. Walsh MC, Hunter GR, Livingstone MB. Sarcopenia in premenopausal and postmenopausal women with osteopenia, osteoporosis and normal bone mineral density. Osteoporos Int (2005) 17:61-7. doi: 10.1007/s00198-0051900-x

38. Montano-Loza AJ, Meza-Junco J, Prado CM, Lieffers JR, Baracos VE, Bain VG, et al. Muscle wasting is associated with mortality in patients with cirrhosis. Clin Gastroenterol Hepatol (2012) 10:166-73, 73.e1. doi: 10.1016/ j.cgh.2011.08.028

39. Golse N, Bucur PO, Ciacio O, Pittau G, Sa Cunha A, Adam R, et al. A new definition of sarcopenia in patients with cirrhosis undergoing liver transplantation. Liver Transpl (2017) 23:143-54. doi: 10.1002/lt.24671

40. Studenski SA, Peters KW, Alley DE, Cawthon PM, McLean RR, Harris TB, et al. The FNIH sarcopenia project: rationale, study description, conference recommendations, and final estimates. J Gerontol A Biol Sci Med Sci (2014) 69:547-58. doi: 10.1093/gerona/glu010

41. Yu R, Shi Q, Liu L, Chen L. Relationship of sarcopenia with steatohepatitis and advanced liver fibrosis in non-alcoholic fatty liver disease: a metaanalysis. BMC Gastroenterol (2018) 18:51. doi: 10.1186/s12876-018-0776-0

42. Cai C, Song X, Chen Y, Chen X, Yu C. Relationship between relative skeletal muscle mass and nonalcoholic fatty liver disease: a systematic review and meta-analysis. Hepatol Int (2020) 14:115-26. doi: 10.1007/s12072-01909964-1

43. Wijarnpreecha K, Panjawatanan P, Thongprayoon C, Jaruvongvanich V, Ungprasert P. Sarcopenia and risk of nonalcoholic fatty liver disease: A meta-analysis. Saudi J Gastroenterol (2018) 24:12-7. doi: 10.4103/ sjg.SJG_237_17

44. Pan X, Han Y, Zou T, Zhu G, Xu K, Zheng J, et al. Sarcopenia contributes to the progression of nonalcoholic fatty liver disease-related fibrosis: a metaanalysis. Dig Dis (2018) 36:427-36. doi: 10.1159/000491015

45. Shen H, Liangpunsakul S. Association between sarcopenia and prevalence of nonalcoholic fatty liver disease: a cross-sectional study from the Third National Health and Nutrition Examination Survey (Mo1555). Gastroenterology (2016) 150:S1143-S4. doi: 10.1016/s0016-5085 (16)33859-8

46. Hsing JC, Nguyen MH, Yang B, Min Y, Han SS, Pung E, et al. Associations between body fat, muscle mass, and nonalcoholic fatty liver disease: a population-based study. Hepatol Commun (2019) 3:1061-72. doi: 10.1002/ hep4.1392

47. Alferink LJM, Trajanoska K, Erler NS, Schoufour JD, de Knegt RJ, Ikram MA, et al. Nonalcoholic fatty liver disease in the Rotterdam Study: about muscle mass, sarcopenia, fat mass, and fat distribution. J Bone Miner Res (2019) 34:1254-63. doi: 10.1002/jbmr.3713

48. Choe EK, Kang HY, Park B, Yang JI, Kim JS. The association between nonalcoholic fatty liver disease and CT-measured skeletal muscle mass. J Clin Med (2018) 7:310. doi: 10.3390/jcm7100310

49. Kim G, Lee SE, Lee YB, Jun JE, Ahn J, Bae JC, et al. Relationship between relative skeletal muscle mass and nonalcoholic fatty liver disease: a 7-year longitudinal study. Hepatology (2018) 68:1755-68. doi: 10.1002/hep.30049

50. Kim HY, Kim CW, Park C-H, Choi JY, Han K, Merchant AT, et al. Low skeletal muscle mass is associated with non-alcoholic fatty liver disease in Korean adults: the Fifth Korea National Health and Nutrition Examination Survey. Hepatobiliary Pancreat Dis Int (2016) 15:39-47. doi: 10.1016/s14993872(15)60030-3
51. Lee MJ, Kim E-H, Bae S-J, Kim G-A, Park SW, Choe J, et al. Age-related decrease in skeletal muscle mass is an independent risk factor for incident nonalcoholic fatty liver disease: a 10-year retrospective cohort study. Gut Liver (2019) 13:67-76. doi: 10.5009/gnl18070

52. Koo BK, Kim D, Joo SK, Kim JH, Chang MS, Kim BG, et al. Sarcopenia is an independent risk factor for non-alcoholic steatohepatitis and significant fibrosis. J Hepatol (2017) 66:123-31. doi: 10.1016/j.jhep.2016.08.019

53. Peng T-C, Wu L-W, Chen W-L, Liaw F-Y, Chang Y-W, Kao T-W. Nonalcoholic fatty liver disease and sarcopenia in a Western population (NHANES III): The importance of sarcopenia definition. Clin Nutr (2019) 38:422-8. doi: 10.1016/j.clnu.2017.11.021

54. Wijarnpreecha K, Kim D, Raymond P, Scribani M, Ahmed A. Associations between sarcopenia and nonalcoholic fatty liver disease and advanced fibrosis in the USA. Eur J Gastroenterol Hepatol (2019) 31:1121-8. doi: 10.1097/meg.0000000000001397

55. Petta S, Ciminnisi S, Di Marco V, Cabibi D, Cammà C, Licata A, et al. Sarcopenia is associated with severe liver fibrosis in patients with nonalcoholic fatty liver disease. Aliment Pharmacol Ther (2017) 45:510-8. doi: 10.1111/apt.13889

56. Marra M, Sammarco R, De Lorenzo A, Iellamo F, Siervo M, Pietrobelli A, et al. Assessment of body composition in health and disease using bioelectrical impedance analysis (BIA) and dual energy $\mathrm{x}$-ray absorptiometry (DXA): a critical overview. Contrast Media Mol Imag (2019) 2019:3548284. doi: 10.1155/2019/3548284

57. Evans WJ, Hellerstein M, Orwoll E, Cummings S, Cawthon PM. D3Creatine dilution and the importance of accuracy in the assessment of skeletal muscle mass. J Cachexia Sarcopenia Muscle (2019) 10:14-21. doi: $10.1002 /$ jcsm. 12390

58. Teigen LM, Kuchnia AJ, Mourtzakis M, Earthman CP. The use of technology for estimating body composition strengths and weaknesses of common modalities in a clinical setting. Nutr Clin Pract (2017) 32:20-9. doi: 10.1177/0884533616676264

59. Achamrah N, Colange G, Delay J, Rimbert A, Folope V, Petit A, et al. Comparison of body composition assessment by DXA and BIA according to the body mass index: A retrospective study on 3655 measures. PloS One (2018) 13:e0200465. doi: 10.1371/journal.pone.0200465

60. Bosaeus M, Karlsson T, Holmäng A, Ellegård L. Accuracy of quantitative magnetic resonance and eight-electrode bioelectrical impedance analysis in normal weight and obese women. Clin Nutr (2014) 33:471-7. doi: 10.1016/ j.clnu.2013.06.017

61. Borga M, West J, Bell JD, Harvey NC, Romu T, Heymsfield SB, et al. Advanced body composition assessment: from body mass index to body composition profiling. J Invest Med (2018) 66:1-9. doi: 10.1136/jim-2018000722

62. Li Q, Dhyani M, Grajo JR, Sirlin C, Samir AE. Current status of imaging in nonalcoholic fatty liver disease. World J Hepatol (2018) 10:530-42. doi: 10.4254/wjh.v10.i8.530

63. Heymsfield SB, Gonzalez MC, Lu J, Jia G, Zheng J. Skeletal muscle mass and quality: evolution of modern measurement concepts in the context of sarcopenia. Proc Nutr Soc (2015) 74:355-66. doi: 10.1017/s002966 5115000129

64. Linge J, Heymsfield SB, Dahlquist Leinhard O. On the definition of sarcopenia in the presence of aging and obesity - initial results from UK Biobank. J Gerontol A Biol Sci Med Sci (2020) 75:1309-16. doi: 10.1093/ gerona/glz229

65. Addison O, Marcus RL, LaStayo PC, Ryan AS. Intermuscular fat: a review of the consequences and causes. Int J Endocrinol (2014) 2014:309570. doi: 10.1155/2014/309570

66. Bhanji RA, Moctezuma-Velazquez C, Duarte-Rojo A, Ebadi M, Ghosh S, Rose C, et al. Myosteatosis and sarcopenia are associated with hepatic encephalopathy in patients with cirrhosis. Hepatol Int (2018) 12:377-86. doi: 10.1007/s12072-018-9875-9

67. Montano-Loza AJ, Angulo P, Meza-Junco J, Prado CM, Sawyer MB, Beaumont C, et al. Sarcopenic obesity and myosteatosis are associated with higher mortality in patients with cirrhosis. J Cachexia Sarcopenia Muscle (2016) 7:126-35. doi: 10.1002/jcsm.12039

68. Sudlow C, Gallacher J, Allen N, Beral V, Burton P, Danesh J, et al. UK Biobank: an open access resource for identifying the causes of a wide range of 
complex diseases of middle and old age. PloS Med (2015) 12:e1001779. doi: 10.1371/journal.pmed.1001779

69. Linge J, Ekstedt M, Dahlqvist Leinhard O. Adverse muscle composition is linked to poor functional performance and metabolic comorbidities in NAFLD. JHEP Rep (2020). doi: 10.1016/j.jhepr.2020.100197

70. Linge J, Whitcher B, Borga M, Dahlqvist Leinhard O. Sub-phenotyping metabolic disorders using body composition: an individualized, nonparametric approach utilizing large data sets. Obes (Silver Spring) (2019) 27:1190-9. doi: 10.1002/oby.22510

71. Forsgren MF, Ekstedt M, Kechagias S, Lundberg P, Dahlqvist Leinhard O. Muscle fat is higher in NAFLD, and increases with fibrosis stage - a retrospective liver biopsy controlled magnetic resonance imaging-based body composition study. J Hepatol (2020) 73:S674. Abstract SAT046. doi: 10.1016/S0168-8278(20)31810-9

72. Nachit M, Vande Velde G, Kwanten WJ, Schakman O, Thissen J-P, De Rudder M, et al. Non-invasive detection of myosteatosis as a tool to predict NASH in the context of metabolic syndrome and obesity. Hepatology (2019) 70(Suppl 1):1052A-3A, Abstract 1744.

73. Borga M, Ahlgren A, Romu T, Widholm P, Leinhard OD, West J. Reproducibility and repeatability of MRI-based body composition analysis. Magn Reson Med (2020) 00:1-11. doi: 10.1002/mrm.28360

74. Lai JC, Dodge JL, Sen S, Covinsky K, Feng S. Functional decline in patients with cirrhosis awaiting liver transplantation: Results from the functional assessment in liver transplantation (FrAILT) study. Hepatol (Baltimore Md) (2016) 63:574-80. doi: 10.1002/hep.28316

75. Tandon P, Low G, Mourtzakis M, Zenith L, Myers RP, Abraldes JG, et al. A model to identify sarcopenia in patients with cirrhosis. Clin Gastroenterol Hepatol (2016) 14:1473-80.e3. doi: 10.1016/j.cgh.2016.04.040

76. Lonardo A, Ballestri S, Marchesini G, Angulo P, Loria P. Nonalcoholic fatty liver disease: a precursor of the metabolic syndrome. Dig Liver Dis (2015) 47:181-90. doi: 10.1016/j.dld.2014.09.020

77. Cortez-Pinto H, Camilo ME, Baptista A, De Oliveira AG, De Moura MC. Non-alcoholic fatty liver: another feature of the metabolic syndrome? Clin Nutr (1999) 18:353-8. doi: 10.1016/s0261-5614(99)80015-6

78. Cleasby ME, Jamieson PM, Atherton PJ. Insulin resistance and sarcopenia: mechanistic links between common co-morbidities. J Endocrinol (2016) 229: R67-81. doi: 10.1530/joe-15-0533

79. Montgomery MK, De Nardo W, Watt MJ. Impact of lipotoxicity on tissue "cross talk" and metabolic regulation. Physiology (2019) 34:134-49. doi: $10.1152 /$ physiol.00037.2018

80. Haüssinger D. Nitrogen metabolism in liver: structural and functional organization and physiological relevance. Biochem J (1990) 267:281-90. doi: 10.1042/bj2670281

81. Fry CS, Rasmussen BB. Skeletal muscle protein balance and metabolism in the elderly. Curr Aging Sci (2011) 4:260-8. doi: 10.2174/18746098 11104030260

82. Tournadre A, Vial G, Capel F, Soubrier M, Boirie Y. Sarcopenia. Joint Bone Spine (2019) 86:309-14. doi: 10.1016/j.jbspin.2018.08.001

83. Deger SM, Hung AM, Gamboa JL, Siew ED, Ellis CD, Booker C, et al. Systemic inflammation is associated with exaggerated skeletal muscle protein catabolism in maintenance hemodialysis patients. JCI Insight (2017) 2:e95185. doi: 10.1172/jci.insight.95185

84. Devries MC, McGlory C, Bolster DR, Kamil A, Rahn M, Harkness L, et al. Leucine, not total protein, content of a supplement is the primary determinant of muscle protein anabolic responses in healthy older women. J Nutrition (2018) 148:1088-95. doi: 10.1093/jn/nxy091

85. Gryson C, Walrand S, Giraudet C, Rousset P, Migné C, Bonhomme C, et al. "Fast proteins" with a unique essential amino acid content as an optimal nutrition in the elderly: Growing evidence. Clin Nutr (2014) 33:642-8. doi: 10.1016/j.clnu.2013.09.004

86. De Bandt JP. Leucine and mammalian target of rapamycin-dependent activation of muscle protein synthesis in aging. J Nutr (2016) 146:2616s24s. doi: $10.3945 /$ jn. 116.234518

87. Jobgen WS, Fried SK, Fu WJ, Meininger CJ, Wu G. Regulatory role for the arginine-nitric oxide pathway in metabolism of energy substrates. J Nutr Biochem (2006) 17:571-88. doi: 10.1016/j.jnutbio.2005.12.001

88. Chakravarthy MV, Neutel J, Confer S, Zhao P, Tatsuta N, Rebello S, et al. Safety, Tolerability, and Physiological Effects of AXA1665, a Novel
Composition of Amino Acids, in Subjects With Child-Pugh A and B Cirrhosis. Clin Transl Gastroenterol (2020) 11:e00222. doi: 10.14309/ ctg.0000000000000222

89. Huber Y, Pfirrmann D, Gebhardt I, Labenz C, Gehrke N, Straub BK, et al. Improvement of non-invasive markers of NAFLD from an individualised, web-based exercise program. Aliment Pharmacol Ther (2019) 50:930-9. doi: 10.1111/apt.15427

90. Zisman A, Peroni OD, Abel ED, Michael MD, Mauvais-Jarvis F, Lowell BB, et al. Targeted disruption of the glucose transporter 4 selectively in muscle causes insulin resistance and glucose intolerance. Nat Med (2000) 6:924-8. doi: $10.1038 / 78693$

91. Castellino P, Luzi L, Simonson DC, Haymond M, DeFronzo RA. Effect of insulin and plasma amino acid concentrations on leucine metabolism in man. Role of substrate availability on estimates of whole body protein synthesis. J Clin Invest (1987) 80:1784-93. doi: 10.1172/jci113272

92. Hyde R, Peyrollier K, Hundal HS. Insulin promotes the cell surface recruitment of the SAT2/ATA2 system A amino acid transporter from an endosomal compartment in skeletal muscle cells. J Biol Chem (2002) 277:13628-34. doi: 10.1074/jbc.M108609200

93. Muniyappa R, Quon MJ. Insulin action and insulin resistance in vascular endothelium. Curr Opin Clin Nutr Metab Care (2007) 10:523-30. doi: 10.1097/MCO.0b013e32819f8ecd

94. Fujita S, Rasmussen BB, Cadenas JG, Drummond MJ, Glynn EL, Sattler FR, et al. Aerobic exercise overcomes the age-related insulin resistance of muscle protein metabolism by improving endothelial function and Akt/mammalian target of rapamycin signaling. Diabetes (2007) 56:1615-22. doi: 10.2337/db06-1566

95. Rasmussen BB, Fujita S, Wolfe RR, Mittendorfer B, Roy M, Rowe VL, et al. Insulin resistance of muscle protein metabolism in aging. FASEB J (2006) 20:768-9. doi: 10.1096/fj.05-4607fje

96. Fujita S, Glynn EL, Timmerman KL, Rasmussen BB, Volpi E. Supraphysiological hyperinsulinaemia is necessary to stimulate skeletal muscle protein anabolism in older adults: evidence of a true age-related insulin resistance of muscle protein metabolism. Diabetologia (2009) 52:1889-98. doi: 10.1007/s00125-009-1430-8

97. Wilkes EA, Selby AL, Atherton PJ, Patel R, Rankin D, Smith K, et al. Blunting of insulin inhibition of proteolysis in legs of older subjects may contribute to age-related sarcopenia. Am J Clin Nutr (2009) 90:1343-50. doi: 10.3945/ajcn.2009.27543

98. Chitturi S, Abeygunasekera S, Farrell GC, Holmes-Walker J, Hui JM, Fung C, et al. NASH and insulin resistance: Insulin hypersecretion and specific association with the insulin resistance syndrome. Hepatology (2002) 35:3739. doi: 10.1053/jhep.2002.30692

99. Pagano G, Pacini G, Musso G, Gambino R, Mecca F, Depetris N, et al. Nonalcoholic steatohepatitis, insulin resistance, and metabolic syndrome: Further evidence for an etiologic association. Hepatology (2002) 35:367-72. doi: 10.1053/jhep.2002.30690

100. Weisberg SP, McCann D, Desai M, Rosenbaum M, Leibel RL, Ferrante AWJr. Obesity is associated with macrophage accumulation in adipose tissue. J Clin Invest (2003) 112:1796-808. doi: 10.1172/jci19246

101. Burhans MS, Hagman DK, Kuzma JN, Schmidt KA, Kratz M. Contribution of adipose tissue inflammation to the development of type 2 diabetes mellitus. Compr Physiol (2018) 9:1-58. doi: 10.1002/cphy.c170040

102. Nilsson MI, Dobson JP, Greene NP, Wiggs MP, Shimkus KL, Wudeck EV, et al. Abnormal protein turnover and anabolic resistance to exercise in sarcopenic obesity. FASEB J (2013) 27:3905-16. doi: 10.1096/fj.12-224006

103. Murton AJ, Marimuthu K, Mallinson JE, Selby AL, Smith K, Rennie MJ, et al. Obesity appears to be associated with altered muscle protein synthetic and breakdown responses to increased nutrient delivery in older men, but not reduced muscle mass or contractile function. Diabetes (2015) 64:3160-71. doi: $10.2337 / \mathrm{db} 15-0021$

104. Conley KE, Jubrias SA, Esselman PC. Oxidative capacity and ageing in human muscle. J Physiol (2000) 526 Pt 1:203-10. doi: 10.1111/j.14697793.2000.t01-1-00203.x

105. Rygiel KA, Picard M, Turnbull DM. The ageing neuromuscular system and sarcopenia: a mitochondrial perspective. J Physiol (2016) 594:4499-512. doi: 10.1113/JP271212

106. Lazo M, Solga SF, Horska A, Bonekamp S, Diehl AM, Brancati FL, et al. Effect of a 12-month intensive lifestyle intervention on hepatic steatosis in 
adults with type 2 diabetes. Diabetes Care (2010) 33:2156-63. doi: 10.2337/ dc10-0856

107. Bacchi E, Negri C, Targher G, Faccioli N, Lanza M, Zoppini G, et al. Both resistance training and aerobic training reduce hepatic fat content in type 2 diabetic subjects with nonalcoholic fatty liver disease (the RAED2 Randomized Trial). Hepatology (2013) 58:1287-95. doi: 10.1002/hep.26393

108. Randle PJ. Regulatory interactions between lipids and carbohydrates: the glucose fatty acid cycle after 35 years. Diabetes Metab Rev (1998) 14:263-83. doi: 10.1002/(sici)1099-0895(199812)14:4<263::aid-dmr233>3.0.co;2-c

109. Galgani JE, Moro C, Ravussin E. Metabolic flexibility and insulin resistance. Am J Physiol Endocrinol Metab (2008) 295:E1009-17. doi: 10.1152/ ajpendo.90558.2008

110. Cahill GFJr., Herrera MG, Morgan AP, Soeldner JS, Steinke J, Levy PL, et al. Hormone-fuel interrelationships during fasting. J Clin Invest (1966) 45:1751-69. doi: 10.1172/JCI105481

111. Prior SJ, Ryan AS, Stevenson TG, Goldberg AP. Metabolic inflexibility during submaximal aerobic exercise is associated with glucose intolerance in obese older adults. Obesity (2013) 22:451-7. doi: 10.1002/oby.20609

112. Ukropcova B, Sereda O, de Jonge L, Bogacka I, Nguyen T, Xie H, et al. Family history of diabetes links impaired substrate switching and reduced mitochondrial content in skeletal muscle. Diabetes (2007) 56:720-7. doi: $10.2337 / \mathrm{db} 06-0521$

113. Goodpaster BH, Wolfe RR, Kelley DE. Effects of obesity on substrate utilization during exercise. Obes Res (2002) 10:575-84. doi: 10.1038/ oby. 2002.78

114. Koopmans SJ, Kushwaha RS, DeFronzo RA. Chronic physiologic hyperinsulinemia impairs suppression of plasma free fatty acids and increases de novo lipogenesis but does not cause dyslipidemia in conscious normal rats. Metabolism (1999) 48:330-7. doi: 10.1016/s00260495(99)90081-1

115. Kelley DE, Goodpaster B, Wing RR, Simoneau JA. Skeletal muscle fatty acid metabolism in association with insulin resistance, obesity, and weight loss. Am J Physiol (1999) 277:E1130-41. doi: 10.1152/ajpendo.1999.277.6.E1130

116. Siddiqui MS, Boyett S, Forsgren M, Patel S, Chen S, Siddiqui MB, et al. Patients transplanted for NASH cirrhosis have impaired whole body fatty acid oxidation. Hepatology (2019) 70(Suppl 1):63A, Abstract 93.

117. Masgrau A, Mishellany-Dutour A, Murakami H, Beaufrère A-M, Walrand S, Giraudet $\mathrm{C}$, et al. Time-course changes of muscle protein synthesis associated with obesity-induced lipotoxicity. J Physiol (2012) 590:5199-210. doi: 10.1113/jphysiol.2012.238576

118. Lumeng CN, Bodzin JL, Saltiel AR. Obesity induces a phenotypic switch in adipose tissue macrophage polarization. J Clin Invest (2007) 117:175-84. doi: $10.1172 /$ jci29881

119. Tilg H, Moschen AR. Evolution of inflammation in nonalcoholic fatty liver disease: the multiple parallel hits hypothesis. Hepatology (2010) 52:1836-46. doi: $10.1002 /$ hep. 24001

120. Gehrke N, Schattenberg JM. Metabolic Inflammation-A Role for Hepatic Inflammatory Pathways as Drivers of Comorbidities in Nonalcoholic Fatty Liver Disease? Gastroenterology (2020) 158:1929-47 e6. doi: 10.1053/ j.gastro.2020.02.020

121. Bing C. Is interleukin-1 $\beta$ a culprit in macrophage-adipocyte crosstalk in obesity? Adipocyte (2015) 4:149-52. doi: 10.4161/21623945.2014.979661

122. Castoldi A, Naffah de Souza C, Câmara NOS, Moraes-Vieira PM. The macrophage switch in obesity development. Front Immunol (2016) 6:637. doi: 10.3389/fimmu.2015.00637

123. Kob R, Bollheimer LC, Bertsch T, Fellner C, Djukic M, Sieber CC, et al. Sarcopenic obesity: molecular clues to a better understanding of its pathogenesis? Biogerontology (2015) 16:15-29. doi: 10.1007/s10522-0149539-7

124. Mauer J, Denson JL, Brüning JC. Versatile functions for IL-6 in metabolism and cancer. Trends Immunol (2015) 36:92-101. doi: 10.1016/j.it.2014.12.008

125. Jin JO, Han X, Yu Q. Interleukin-6 induces the generation of IL-10producing $\operatorname{Tr} 1$ cells and suppresses autoimmune tissue inflammation. J Autoimmun (2013) 40:28-44. doi: 10.1016/j.jaut.2012.07.009

126. McKay BR, Ogborn DI, Baker JM, Toth KG, Tarnopolsky MA, Parise G. Elevated SOCS3 and altered IL-6 signaling is associated with age-related human muscle stem cell dysfunction. Am J Physiol Cell Physiol (2013) 304: C717-C28. doi: 10.1152/ajpcell.00305.2012
127. Al-Shanti N, Stewart CE. Inhibitory effects of IL-6 on IGF-1 activity in skeletal myoblasts could be mediated by the activation of SOCS-3. J Cell Biochem (2012) 113:923-33. doi: 10.1002/jcb.23420

128. Zhai Y, Xiao Q. The common mechanisms of sarcopenia and NAFLD. BioMed Res Int (2017) 2017:6297651-. doi: 10.1155/2017/6297651

129. De Bandt J-P, Jegatheesan P, Tennoune-El-Hafaia N. Muscle loss in chronic liver diseases: the example of nonalcoholic liver disease. Nutrients (2018) 10:1195. doi: 10.3390/nu10091195

130. Rodriguez J, Vernus B, Chelh I, Cassar-Malek I, Gabillard JC, Hadj Sassi A, et al. Myostatin and the skeletal muscle atrophy and hypertrophy signaling pathways. Cell Mol Life Sci (2014) 71:4361-71. doi: 10.1007/s00018-014$1689-\mathrm{x}$

131. García PS, Cabbabe A, Kambadur R, Nicholas G, Csete M. Brief-reports: elevated myostatin levels in patients with liver disease: a potential contributor to skeletal muscle wasting. Anesth Analg (2010) 111:707-9. doi: 10.1213/ANE.0b013e3181eac1c9

132. Elkina Y, von Haehling S, Anker SD, Springer J. The role of myostatin in muscle wasting: an overview. J Cachexia Sarcopenia Muscle (2011) 2:143-51. doi: 10.1007/s13539-011-0035-5

133. Cleasby ME, Jarmin S, Eilers W, Elashry M, Andersen DK, Dickson G, et al. Local overexpression of the myostatin propeptide increases glucose transporter expression and enhances skeletal muscle glucose disposal. Am J Physiol Endocrinol Metab (2014) 306:E814-23. doi: 10.1152/ajpendo. 00586.2013

134. Guo T, Jou W, Chanturiya T, Portas J, Gavrilova O, McPherron AC. Myostatin inhibition in muscle, but not adipose tissue, decreases fat mass and improves insulin sensitivity. PloS One (2009) 4:e4937. doi: 10.1371/ journal.pone.0004937

135. Zhang C, McFarlane C, Lokireddy S, Bonala S, Ge X, Masuda S, et al. Myostatin-deficient mice exhibit reduced insulin resistance through activating the AMP-activated protein kinase signalling pathway. Diabetologia (2011) 54:1491-501. doi: 10.1007/s00125-011-2079-7

136. Zhang C, McFarlane C, Lokireddy S, Masuda S, Ge X, Gluckman PD, et al. Inhibition of myostatin protects against diet-induced obesity by enhancing fatty acid oxidation and promoting a brown adipose phenotype in mice. Diabetologia (2011) 55:183-93. doi: 10.1007/s00125-011-2304-4

137. Wilkes JJ, Lloyd DJ, Gekakis N. Loss-of-function mutation in myostatin reduces tumor necrosis factor alpha production and protects liver against obesity-induced insulin resistance. Diabetes (2009) 58:1133-43. doi: 10.2337/ db08-0245

138. Merli M, Dasarathy S. Sarcopenia in non-alcoholic fatty liver disease: Targeting the real culprit? J Hepatol (2015) 63:309-11. doi: 10.1016/ j.jhep.2015.05.014

139. Delogu W, Caligiuri A, Provenzano A, Rosso C, Bugianesi E, Coratti A, et al. Myostatin regulates the fibrogenic phenotype of hepatic stellate cells via cjun N-terminal kinase activation. Dig Liver Dis (2019) 51:1400-8. doi: 10.1016/j.dld.2019.03.002

140. Boström P, Wu J, Jedrychowski MP, Korde A, Ye L, Lo JC, et al. A PGC1- $\alpha$ dependent myokine that drives brown-fat-like development of white fat and thermogenesis. Nature (2012) 481:463-8. doi: 10.1038/nature10777

141. Vaughan RA, Gannon NP, Barberena MA, Garcia-Smith R, Bisoffi M, Mermier $\mathrm{CM}$, et al. Characterization of the metabolic effects of irisin on skeletal muscle in vitro. Diabetes Obes Metab (2014) 16:711-8. doi: 10.1111/dom.12268

142. Mo L, Shen J, Liu Q, Zhang Y, Kuang J, Pu S, et al. Irisin is regulated by CAR in liver and is a mediator of hepatic glucose and lipid metabolism. Mol Endocrinol (2016) 30:533-42. doi: 10.1210/me.2015-1292

143. Moreno-Navarrete JM, Ortega F, Serrano M, Guerra E, Pardo G, Tinahones $\mathrm{F}$, et al. Irisin is expressed and produced by human muscle and adipose tissue in association with obesity and insulin resistance. J Clin Endocrinol Metab (2013) 98:E769-78. doi: 10.1210/jc.2012-2749

144. Huh JY, Dincer F, Mesfum E, Mantzoros CS. Irisin stimulates muscle growth-related genes and regulates adipocyte differentiation and metabolism in humans. Int J Obes (2014) 38:1538-44. doi: 10.1038/ ijo. 2014.42

145. Zhang Y, Li R, Meng Y, Li S, Donelan W, Zhao Y, et al. Irisin stimulates browning of white adipocytes through mitogen-activated protein kinase p38 MAP kinase and ERK MAP kinase signaling. Diabetes (2013) 63:514-25. doi: $10.2337 / \mathrm{db} 13-1106$ 
146. Benetti E, Mastrocola R, Chiazza F, Nigro D, D’Antona G, Bordano V, et al. Effects of vitamin $\mathrm{D}$ on insulin resistance and myosteatosis in diet-induced obese mice. PloS One (2018) 13:e0189707. doi: 10.1371/journal.pone.0189707

147. Maestro B, Dávila N, Carranza MC, Calle C. Identification of a vitamin D response element in the human insulin receptor gene promoter. J Steroid Biochem Mol Biol (2003) 84:223-30. doi: 10.1016/s0960-0760(03)00032-3

148. Riachy R, Vandewalle B, Kerr Conte J, Moerman E, Sacchetti P, Lukowiak B, et al. 1,25-dihydroxyvitamin D3 protects RINm5F and human islet cells against cytokine-induced apoptosis: implication of the antiapoptotic protein A20. Endocrinology (2002) 143:4809-19. doi: 10.1210/en.2002-220449

149. El-Fakhri N, McDevitt H, Shaikh MG, Halsey C, Ahmed SF, Vitamin D. and its effects on glucose homeostasis, cardiovascular function and immune function. Horm Res Paediatr (2014) 81:363-78. doi: 10.1159/000357731

150. Gascon-Barré M, Demers C, Mirshahi A, Neron S, Zalzal S, Nanci A. The normal liver harbors the vitamin D nuclear receptor in nonparenchymal and biliary epithelial cells. Hepatology (2003) 37:1034-42. doi: 10.1053/ jhep.2003.50176

151. Sharifi N, Amani R, Hajiani E, Cheraghian B. Does vitamin D improve liver enzymes, oxidative stress, and inflammatory biomarkers in adults with nonalcoholic fatty liver disease? A randomized clinical trial. Endocrine (2014) 47:70-80. doi: 10.1007/s12020-014-0336-5

152. Eliades M, Spyrou E, Agrawal N, Lazo M, Brancati FL, Potter JJ, et al. Metaanalysis: vitamin D and non-alcoholic fatty liver disease. Aliment Pharmacol Ther (2013) 38:246-54. doi: 10.1111/apt.12377

153. Barchetta I, Carotti S, Labbadia G, Gentilucci UV, Muda AO, Angelico F, et al. Liver vitamin D receptor, CYP2R1, and CYP27A1 expression: relationship with liver histology and vitamin D3 levels in patients with nonalcoholic steatohepatitis or hepatitis C virus. Hepatology (2012) 56:21807. doi: $10.1002 /$ hep. 25930

154. Visser M, Deeg DJ, Lips P, Low vitamin D. and high parathyroid hormone levels as determinants of loss of muscle strength and muscle mass (sarcopenia): the Longitudinal Aging Study Amsterdam. J Clin Endocrinol Metab (2003) 88:5766-72. doi: 10.1210/jc.2003-030604

155. Burne THJ, Johnston ANB, McGrath JJ, Mackay-Sim A. Swimming behaviour and post-swimming activity in Vitamin D receptor knockout mice. Brain Res Bull (2006) 69:74-8. doi: 10.1016/j.brainresbull.2005.10.014

156. Endo I, Inoue D, Mitsui T, Umaki Y, Akaike M, Yoshizawa T, et al. Deletion of vitamin $\mathrm{D}$ receptor gene in mice results in abnormal skeletal muscle development with deregulated expression of myoregulatory transcription factors. Endocrinology (2003) 144:5138-44. doi: 10.1210/en.2003-0502

157. Chen S, Villalta SA, Agrawal DK. FOXO1 mediates vitamin D deficiencyinduced insulin resistance in skeletal muscle. J Bone Miner Res (2016) 31:585-95. doi: 10.1002/jbmr.2729

158. Songpatanasilp T, Chailurkit LO, Nichachotsalid A, Chantarasorn M. Combination of alfacalcidol with calcium can improve quadriceps muscle strength in elderly ambulatory Thai women who have hypovitaminosis D: a randomized controlled trial. J Med Assoc Thai (2009) 92 Suppl5:S30-41.
159. Zhu K, Austin N, Devine A, Bruce D, Prince RL. A randomized controlled trial of the effects of vitamin $\mathrm{D}$ on muscle strength and mobility in older women with vitamin D insufficiency. J Am Geriatr Soc (2010) 58:2063-8. doi: 10.1111/j.1532-5415.2010.03142.x

160. Gupta R, Sharma U, Gupta N, Kalaivani M, Singh U, Guleria R, et al. Effect of cholecalciferol and calcium supplementation on muscle strength and energy metabolism in vitamin D-deficient Asian Indians: a randomized, controlled trial. Clin Endocrinol (Oxf) (2010) 73:445-51. doi: 10.1111/j.13652265.2010.03816.x

161. Ward KA, Das G, Roberts SA, Berry JL, Adams JE, Rawer R, et al. A randomized, controlled trial of vitamin $\mathrm{D}$ supplementation upon musculoskeletal health in postmenarchal females. J Clin Endocrinol Metab (2010) 95:4643-51. doi: 10.1210/jc.2009-2725

162. Pfeifer M, Begerow B, Minne HW, Suppan K, Fahrleitner-Pammer A, Dobnig $\mathrm{H}$. Effects of a long-term vitamin $\mathrm{D}$ and calcium supplementation on falls and parameters of muscle function in community-dwelling older individuals. Osteoporos Int (2009) 20:315-22. doi: 10.1007/s00198-008-0662-7

163. Muir SW, Montero-Odasso M. Effect of vitamin D supplementation on muscle strength, gait and balance in older adults: a systematic review and meta-analysis. J Am Geriatr Soc (2011) 59:2291-300. doi: 10.1111/j.15325415.2011.03733.x

164. Stockton KA, Mengersen K, Paratz JD, Kandiah D, Bennell KL. Effect of vitamin D supplementation on muscle strength: a systematic review and meta-analysis. Osteoporos Int (2011) 22:859-71. doi: 10.1007/s00198-0101407-y

Conflict of Interest: MC is an employee of Axcella Health Inc. and may own stock options in the company. MS has nothing to disclose. MF is an employee of AMRA Medical AB. AS has nothing to disclose for this project. AS is the president of Sanyal Biotechnology and has stock options in Genfit, Akarna, Tiziana, Indalo, Durect, Inversago, and Galmed. He has served as a consultant to Astra Zeneca, Nitto Denko, Conatus, Nimbus, Salix, Tobira, Takeda, Jannsen, Gilead, Terns, Birdrock, Merck, Valeant, Boehringer-Ingelheim, Bristol Myers Squibb, Lilly, Hemoshear, Zafgen, Novartis, Novo Nordisk, Pfizer, Exhalenz, and Genfit. He has been an unpaid consultant to Intercept, Echosens, Immuron, Galectin, Fractyl, Syntlogic, Affimune, Chemomab, Zydus, Nordic Bioscience, Albireo, Prosciento, and Surrozen. His institution has received grant support from Gilead, Salix, Tobira, Bristol Myers, Shire, Intercept, Merck, Astra Zeneca, Malinckrodt, Cumberland, and Novartis. He receives royalties from Elsevier and UptoDate.

Copyright (c) 2020 Chakravarthy, Siddiqui, Forsgren and Sanyal. This is an openaccess article distributed under the terms of the Creative Commons Attribution License (CC BY). The use, distribution or reproduction in other forums is permitted, provided the original author(s) and the copyright owner(s) are credited and that the original publication in this journal is cited, in accordance with accepted academic practice. No use, distribution or reproduction is permitted which does not comply with these terms. 